\title{
Troodontidae (Dinosauria: Theropoda) from the Upper Cretaceous of
}

\section{Uzbekistan}

Alexander Averianov ${ }^{\mathrm{a}, \mathrm{b}}$, Hans-Dieter Sues ${ }^{\mathrm{c} *}$

${ }^{a}$ Zoological Institute, Russian Academy of Sciences, Universitetskaya nab. 1, 199034 Saint Petersburg, Russia

${ }^{\mathrm{b}}$ Department of Sedimentary Geology, Geological Faculty, Saint Petersburg State University, 16 Liniya VO 29, 199178 Saint Petersburg, Russia

${ }^{\mathrm{c}}$ Department of Paleobiology, National Museum of Natural History, Smithsonian Institution, MRC 121, P.O. Box 37012, Washington, DC 20013-7012, USA

* Corresponding author.

E-mail addresses: dzharakuduk@mail.ru (A. Averianov), suesh@si.edu (H.-D. Sues).

Article history:

Received

Keywords: Dinosauria, Theropoda, Troodontidae, Cretaceous, Uzbekistan

To date three taxa of troodontid theropod dinosaurs have been recognized from Upper Cretaceous strata in two regions of the Kyzylkum Desert in Uzbekistan. The Cenomanian Khodzhakul Formation in the southwestern Kyzylkum Desert has yielded isolated serrated teeth and some postcranial bones of an indeterminate troodontid. In the central Kyzylkum Desert troodontids are known from the Cenomanian Dzharakuduk Formation (Urbacodon itemirensis) and the Turonian Bissekty Formation (Urbacodon sp.). Urbacodon itemirensis is known from a single dentary whereas Urbacodon sp. is represented by isolated teeth, maxilla and dentary 
fragments, a partial braincase, and some postcranial bones. The troodontid affinities of Urbacodon are supported by several synapomorphies: presence of a subotic recess; reduced basal tubera placed directly under the occipital condyle; maxilla participating in the margin of the external naris; nutrient foramina on dentary situated within a deep lateral groove; dentary without distinct interdental plates; large number of small dentary and maxillary teeth; teeth constricted between root and crown; anterior dentary teeth smaller, more numerous, more closely spaced than those in the middle of the tooth row, and implanted in a groove; posterior dorsal vertebrae with tall and posterodorsally tapering neural spines; and presence of a midline sulcus on the neural arches of distal caudals. Among Troodontidae, Urbacodon resembles Byronosaurus, Gobivenator, and Xixiasaurus in having the absence of serrations on the tooth crowns and premaxillary teeth that are D-shaped in cross-section. However, phylogenetic analysis did not recover a clade of Asiatic troodontids with unserrated teeth.

\section{Introduction}

Troodontidae is a clade of small to medium-sized Cretaceous theropod dinosaurs definitely known only from North America and Asia. Troodontids are rare in all vertebrate assemblages and were most diverse in Asia. They were agile predators, with well-developed vision and hearing and a relatively large brain. This is evident from the large orbit with its raised dorsal rim, vaulted frontals and parietals, a lateral depression on the braincase for the middle ear cavity, and a periotic sinus system (Currie, 1985; Varricchio, 1997; Makovicky and Norell, 2004). Furthermore, the pneumatic basisphenoid bulla may have aided in detection of low-frequency sounds (Currie, 1985; Makovicky and Norell, 2004). The long hind limbs of troodontids, with a slender and elongated crus and metatarsus, and a functionally didactyl pes with a specialized second digit, appear suitable for fast running (Makovicky and Norell, 2004). The narial passage and oral cavity were separated by a secondary bony palate formed by the palatal shelves of the 
maxillae. In the largest known species, Troodon formosus from the Campanian-Maastrichtian of North America and eastern Russia, the orbits face anterolaterally, which may indicate binocular vision (Makovicky and Norell, 2004). The occurrence of this species at high paleolatitudes in present-day Alaska and Chukotka (Clemens and Nelms, 1993; Fiorillo and Gangloff, 2000; Averianov and Sues, 2007; Fiorillo, 2008; Fiorillo et al., 2009; Godefroit et al., 2009) suggests that it could survive the polar winter and darkness. In Alaska, Troodon was the most common theropod (Fiorillo and Gangloff, 2000). It constructed nests for egg incubation and had a birdlike mode of egg-laying, but retained two functional ovaries and oviducts (Varricchio et al., 1997; Varricchio et al., 1999).

In Uzbekistan two regions have yielded skeletal remains of troodontid dinosaurs. Isolated serrated teeth of Troodontidae indet. have been found in the lower Cenomanian Khodzhakul Formation of the Khodzhakul and Sheikhdzheili localities in the southwestern Kyzylkum Desert (Nesov, 1995; Averianov and Sues, 2007). In the Itemir-Dzharakuduk depression of the central Kyzylkum Desert a thick sequence of Upper Cretaceous deposits is exposed along escarpments bordering the depression to the north (Fig. 1). Averianov and Sues (2007) described a dentary of the troodontid Urbacodon itemirensis with unserrated teeth from the lower part of the Cenomanian Dzharakuduk Formation of Itemir. Similar unserrated isolated teeth as well as troodontid bones are known also from the upper Turonian Bissekty Formation of Dzharakuduk. Averianov and Sues (2007) briefly discussed these specimens and referred them to Urbacodon sp. Here we provide a detailed description of the troodontid specimens from the Bissekty Formation. The sole exception is a well-preserved partial troodontid braincase CCMGE 466/12457, which was recently CT-scanned and will be included in a separate study on endocranial structure of Troodontidae. Some troodontid features of this specimen were previously noted by Averianov and Sues (2007: p. 92). In addition to these characters, CCMGE 466/12457 has a well-developed subotic recess, which Makovicky et al. (2003) considered a troodontid synapomorphy. 
Strata of the Bissekty Formation are exposed along an approximately $8 \mathrm{~km}$ long escarpment near the small settlement of Dzharakuduk (variously given in the literature as Dzhara-Kuduk, Dzhirakuduk, Dzhyrakuduk, Bissekty, and Kul'beke) in the central Kyzylkum Desert, 32 km SW of Mynbulak in the Navoi district, Uzbekistan (Nesov, 1995, 1997; Archibald et al., 1998). The escarpment extends from about $42^{\circ} 06^{\prime} 22.60^{\prime \prime} \mathrm{N}$ and $62^{\circ} 37^{\prime} 09.00^{\prime \prime} \mathrm{E}$ to $42^{\circ} 05^{\prime} 44.22^{\prime \prime} \mathrm{N}$ and $62^{\circ} 41^{\prime} 06.49^{\prime \prime} \mathrm{E}$ (Fig. 1). The Bissekty Formation comprises medium-grained, poorly lithified, cross-bedded fluvial sandstones and clast-supported, well-cemented infraformational conglomerates. It reaches a thickness of up to $80 \mathrm{~m}$.

\subsection{Institutional abbreviations}

CCMGE - Chernyshev's Central Museum of Geological Exploration, Saint Petersburg, Russia; SPbGU VZ Din - Department of Vertebrate Zoology, Saint Petersburg State University, Saint Petersburg, Russia; USNM - Department of Paleobiology, National Museum of Natural History, Smithsonian Institution, Washington, D.C., U.S.A.; ZIN PH - Paleoherpetological Collection, Zoological Institute, Russian Academy of Sciences, Saint Petersburg, Russia; ZIN PO - Paleornithological Collection, Zoological Institute, Russian Academy of Sciences, Saint Petersburg, Russia.

\subsection{Locality abbreviations}

The locality information following catalog numbers uses Nesov's prefixes CBI - Central (Kyzylkum) Bissekty and CDZH - Central (Kyzylkum) Dzharakuduk for localities within the middle-upper and lower parts of the Bissekty Formation, respectively. 


\subsection{Measurements}

Vertebrae: $\mathrm{ACH}$, anterior height of centrum (without hypapophysis); ACW, anterior width of centrum; CL, centrum length (ventral); NAL, neural arch length (measured between anterior and posterior margins of dorsal roof of neural canal); NSL, neural spine length (maximum); PCH, posterior height of centrum; PCW, posterior centrum width.

Metapodials and phalanges: L, length; PW, maximum width of proximal end; DW, maximum width of distal end.

All measurements are in millimeters.

\section{Systematic paleontology}

Dinosauria Owen, 1842

Saurischia Seeley, 1887

Theropoda Marsh, 1881

Maniraptora Gauthier, 1986

Paraves Sereno, 1997

Deinonychosauria Colbert and Russell, 1969 sensu Turner et al., 2012

Troodontidae Gilmore, 1924 sensu Turner et al., 2012

Troodontidae indet.

1981a Saurornithoides [sp.]: Nesov, p. 91

1985a Pectinodon [sp.]: Nesov, p. 148

1985b Pectinodon asiamericanus [nomen nudum]: Nesov, pl. 3, fig. 16 
1988 Pectinodon nov. sp.: Nesov, p. 96

1995 Troodon asiamericanus [nomen dubium]: Nesov, p. 41, pl. 1, fig. 23

2007 Troodontidae indet.: Averianov and Sues, fig. 5D-O

Material used in this study. A number of teeth and vertebrae referable to Troodontidae have been collected from strata of the Khodzhakul Formation. Nesov (1995) designated CCMGE 49/12176, an isolated tooth crown, as the holotype of Troodon asiamericanus. Averianov and Sues (2007) found no diagnostic features for this taxon and considered Nesov's binomen a nomen dubium. ZIN PH 1883-1891/16 represent additional dissociated teeth crowns and ZIN PH 2355-2358/16 posterior caudal vertebrae. The tooth crowns bear rather large denticles along the distal carina, similar to the condition in several troodontids (e.g., Troodon formosus) and lack any trace of mesial serrations. On the unworn crowns, the apices of the distal denticles curve toward the apex of the crown distally.

Urbacodon Averianov and Sues, 2007

The type species of Urbacodon is Urbacodon itemirensis. The holotype is ZIN PH 944/16, a nearly complete left dentary (Averianov and Sues, 2007: fig. 2A-C) from the Dzharakuduk Formation (Upper Cretaceous: lower Cenomanian) at the Itemir locality (IT-01) in the ItemirDzharakuduk Depression of the central Kyzylkum Desert, Navoi Viloyat, Uzbekistan.

\section{Urbacodon sp.}

Figs. 2-10

1981b Theropoda [indet.]: Nesov, fig. 10-12 
1995 Theropoda [indet.]: Nesov, pl. 2, fig. 10

1992 Ichthyornithiformes [indet.]: Nesov, pl. 2, fig. 1

1993 Deinonychosauria? [indet.] or Mammalia? [indet.]: Nesov, fig. 6-2

1995 Theropoda [indet.] or Dromaeosauridae(?) [indet.]: Nesov, pl. 2, fig. 17

1995 Ornithomimidae? [indet.]: Nesov, pl. 3, fig. 2

1997 Ichthyornithiformes [indet.]: Nesov, pl. 19, fig. 1

1997 Deinonychosauria? [indet.] or Mammalia? [indet.]: Nesov, p. 149

2007 Urbacodon sp.: Averianov and Sues, figs. 2G-I, 5P-R

Referred material used in this study. ZIN PH 2308/16, maxilla fragment; ZIN PO 4608, juvenile dentary fragment; CCMGE 71/12455, CCMGE 2/11822, ZIN PH 265/16, and ZIN PH 1899/16, isolated teeth; SPbGU VZ Din 7/2, ZIN PH 893/16, and ZIN PH 2339/16, dorsal vertebrae; CCMGE 475/12457, anterior caudal vertebra; ZIN PH 2340/16 and USNM 538124, posterior caudal vertebrae; ZIN PH 2343/16, proximal manual phalanx; ZIN PH 2341/16 and ZIN PH 2342/16, distal portions of metatarsal III; ZIN PH 99/16, pedal phalanx II-2. The teeth of Urbacodon itemirensis from the Dzharakuduk Formation are distinctive in the absence of serrations on their mesial and distal carinae (Averianov and Sues, 2007). Isolated teeth of this morphotype also occur in the Bissekty Formation, and the dentary fragment ZIN PO 4608 from the same unit also contains an erupting tooth crown that lacks mesial and distal serrations. No other types of teeth referable to Troodontidae are known from the Bissekty Formation. In view of the slight difference in stratigraphic age we refer all troodontid skeletal remains from this formation to Urbacodon sp.

Locality and horizon. Dzharakuduk, central Kyzylkum Desert, Navoi Viloyat, Uzbekistan. Bissekty Formation, Upper Cretaceous, middle-upper Turonian. 


\title{
3. Description
}

\author{
3.1. Skull
}

\subsubsection{Maxilla}

ZIN PH 2308/16 preserves the more anterior portion of a left maxilla (Fig. 2). The anteroventral end is broken and there is a large opening caused by breakage below the palatal shelf. The fragment is triangular in lateral and medial view, with a pointed anterior end and gradually increasing in height posteriorly. Its anterodorsal surface is gently convex and forms the ventral floor of the narial opening anteriorly (subnarial shelf; Fig. 2A, C), A narrow strip along the dorsal margin of the ascending process represents the area of contact the nasal. The anterior extent of the nasal facet is comparable to that in Troodon formosus (Currie, 1985: fig. 2). The presence of a subnarial shelf suggests that a posterior process of premaxilla, which would have excluded the maxilla from the narial margin, was absent, as in all other troodontids except Sinovenator changii (Xu et al., 2002: fig. 1a) and Xixiasaurus henanensis (Lü et al., 2010: fig. 2B). The lateral surface of maxilla is covered by arcuate ridges parallel to the anterodorsal border. Prominent neurovascular foramina open just above and parallel to the lateral margins of the alveoli. The palatal portion of the maxilla is highly vaulted, with the lingual surface nearly vertical adjacent to the tooth row. As in other troodontids (e.g., Zanabazar junior; Norell et al., 2009), there is a distinct palatal shelf; its medial margin is damaged more anteriorly. At the level of the maxillary fenestra the shelf bears a distinct, oval recess, which presumably represents an area for contact with the vomer.

The maxilla has a deep, sharply rimmed antorbital fossa, which contains the maxillary fenestra anteriorly and the antorbital fenestra (of which only the anterior margin is preserved) posteriorly. The two openings are separated by a more or less hourglass-shaped interfenestral bar 
as in Zanabazar junior (Norell et al., 2009: fig. 22). There is no separate promaxillary fenestra. The maxillary foramen opens anteriorly into a large sinus in the body of the ascending process of the maxilla. On the medial surface of the ascending process, a dorsal groove leads into the narial chamber and a ventral groove has two foramina anteriorly, a large one leading into the maxillary sinus and, just posterior and ventral to this opening, a smaller foramen of uncertain identity. These features closely resemble those in Byronosaurus jaffei (Makovicky et al., 2003: fig. 10).

The fragment preserves alveoli for 11 closely spaced teeth. The anterior six alveoli are distinctly shorter anteroposteriorly than the posterior alveoli. The interdental ridges, separating the tooth sockets, are incompletely preserved but present in all alveoli, including the most anterior. Apparently the interdental ridges were not as high as the labial and lingual alveolar borders. There is a distinct groove for the dental lamina in the region of the posterior teeth (Fig. 2B). It is likely that this groove was not preserved due to breakage at the anterior end of the tooth row. A thin bony plate, separated by the lingual groove for the dental lamina (Fig. 2B), is divided into interdental plates adjacent to the interalveolar ridges. The surface sculpturing of the interdental plates does not differ from that of the adjacent bone. By contrast, the maxillae of other troodontids (e.g., Lü et al., 2010: fig. 2C) lack individual interdental plates. Large oval openings in the floor of the groove likely served for passage of developing teeth. The large size of these openings in ZIN PH 2308/16 suggests that it belonged to a skeletally immature specimen with a high rate of tooth replacement. Similar large oval openings along the lingual groove for the dental lamina are visible in the holotype of Xixiasaurus henanensis (Lü et al., 2010: fig. 2C), whereas this groove is greatly reduced in the holotype of Gobivenator mongoliensis (Tsuihiji et al., 2014: fig. 5).

The supraalveolar canal, carrying the maxillary ramus of the trigeminal nerve $(\mathrm{V})$ and associated vessels, extends just labial to the labial walls of the alveoli. Its anterior exit is situated more medially than in Byronosaurus jaffei (Makovicky et al., 2003: fig. 6). 


\subsubsection{Dentary}

Averianov and Sues (2007: 89-90, 92) described ZIN PO 4608 (Fig. 3) and interpreted it as a juvenile dentary fragment of Urbacodon sp. from the Bissekty Formation of Dzharakuduk. Nessov (1992) had originally identified this jaw as that of an ichthyornithiform bird but noted differences to the dentary of Ichthyornis. ZIN PO 4608 preserves 12 alveoli and an erupting unserrated tooth crown in the seventh alveolus (counting from the preserved anterior end). Its labial surface bears two rows of closely spaced, cleft-like foramina. Some of the openings in the dorsal row are united to form a distinct groove, which is a diagnostic feature for Troodontidae.

\subsubsection{Teeth}

Teeth of Urbacodon sp. are not common in the Bissekty Formation of Dzharakuduk. Only four teeth have been identified to date and were described in Averianov and Sues (2007: p. 91-92, figs. 2G-I, 5P-R): CCMGE 71/12455, a premaxillary tooth (Fig. 4A-D), ZIN PH 256/16, an anterior dentary tooth (Fig. 4E-H), and CCMGE 2/11822 and ZIN PH 1899/16, which are either maxillary or posterior dentary teeth.

\subsection{Postcranial axial skeleton}

\subsubsection{Dorsal vertebrae}

Three isolated dorsal vertebrae from Dzharakuduk are referable to Troodontidae. ZIN PH 2339/16 (Fig. 5A-E; ACH=22.0; ACW=22.3; CL=27.7; NAL=25.1; NSL=12.0; PCH=20.3; PCW=21.9) is an anterior dorsal similar to those of Troodon formosus (Makovicky and Norell, 2004: fig. 9.4D). Its centrum is slightly procoelous and greatly constricted between the heart- 
shaped intercentral articular surfaces and has a large hypapophysis occupying most of its ventral side. The parapophysis is small and located at the anterior border of the vertebra between the centrum and neural arch. There is a deep triangular infradiapophyseal fossa. The neural spine is relatively short anteroposteriorly and confined to the posterior half of the neural arch. The postzygapophyseal surfaces are convex. A deep posterior interspinous recess separates the postzygapophyses.

ZIN PH 893/16 and SPbGU VZ Din 7/2 are more posterior dorsals without a hypapophysis and with a broader, spool-shaped centrum with rounded intercentral articular surfaces (Fig. 5F-O; $\mathrm{ACH}=24.3,21.2 ; \mathrm{ACW}=26.5,24.2 ; \mathrm{CL}=26.6,23.4 ; \mathrm{NAL}=-$, 18.3; NSL=13.4, 15.4; $\mathrm{PCH}=22.5,19.6 ; \mathrm{PCW}=25.6,21.2$ respectively). These vertebrae closely resemble a dorsal vertebra of Talos sampsoni (Zanno et al., 2011: fig. 5A, B, E). The anterior intercentral articular surface projects more ventrally compared with the posterior surface, especially in SPbGU VZ Din 7/2 (Fig. 5L). As in ZIN PH 2339/16, the parapophysis is small and placed just above the dorsal margin of the centrum. The transverse process (missing in both specimens) is hollow and connected by a slit-like opening to a chamber within the hollow neural arch (visible in SPbGU VZ Din 7/2; Fig. 5L). On the posterior side of the neural arch there are prominent infrapostzygapophyseal depressions (absent from the right side in ZIN PH 893/16; Fig. 5F, K), which are similar to those in Talos sampsoni (Zanno et al., 2011: fig. 5B). The neural spine, almost completely preserved in SPbGU VZ Din 7/2, is relatively longer anteroposteriorly than in other specimens and tall, exceeding the height of the centrum. It seems that the length of the neural spine was uniform thorough its height. The neural spine tapers posterodorsally as in Talos sampsoni and Troodon formosus (Zanno et al., 2011). The dorsal margin of the neural spine is slightly transversely expanded, similar in degree of expansion with Talos sampsoni, but not a spine table as in Troodon formosus (Zanno et al., 2011). The anterior and posterior interspinous recesses are relatively narrow and extend dorsally less than half of the spine height. 


\subsubsection{Caudal vertebrae}

Several dissociated posterior caudal vertebrae from Dzharakuduk have a sulcus on dorsal side of the neural arch in place of the neural spine, a feature considered diagnostic for Troodontidae by Makovicky and Norell (2004). USNM 538124 is an almost complete posterior caudal (Fig. 6; $\mathrm{ACH}=11.8 ; \mathrm{ACW}=13.0 ; \mathrm{CL}=29.0 ; \mathrm{NAL}=27.5 ; \mathrm{PCH}=11.5 ; \mathrm{PCW}=13.0$ ). The centrum is elongate and amphicoelous. The entire ventral side is occupied by a prominent groove flanked laterally by sharp ridges. At the junction between the centrum and neural arch a short ridge-like feature represents a remnant of the transverse process. The neural arch is well developed, with the pre- and postzygapophyses protruding beyond the centrum. The roof formed by the neural arch over the neural canal is only slightly shorter than the centrum. There are prominent anterior and posterior interspinous recesses. The anterior one is placed posterior to the prezygapophysis and is dorsally open. The posterior one is between and anterior to the postzygapophyses and is ventrally open. The zygapophyseal articular surfaces are oval and longitudinally elongate. The prezygapophyseal facets face dorsomedially and the postzygophyseal ones face ventrolaterally. The prezygapophyseal process projects anteriorly well beyond the anterior end of the prezygapophyseal articular surface. Along its lateral edge a robust horizontal ridge extends posteriorly towards the anterior end of the postzygapophyseal articular surface. In place of a neural spine a shallow groove extends along the entire dorsal side of the neural arch and is flanked laterally by sharp ridges. The groove is distinctly constricted at the mid-length of the centrum.

ZIN PH 2340/16 is a more posterior and more elongated caudal (Fig. 7; $\mathrm{ACH}=7.5$; $\mathrm{ACW}=6.6 ; \mathrm{CL}=38.0 ; \mathrm{NAL}=35.4 ; \mathrm{PCH}=7.1 ; \mathrm{PCW}=6.0$ ). Its centrum is laterally compressed, with a groove extending along the entire ventral surface. The neural arch is similar in length to the centrum and has reduced zygapophyses. A deep sulcus extends along the dorsal surface of 
the entire length of the neural arch. CCMGE 475/12457, figured by Nessov (1995: pl. 3, fig. 2) and described by Averianov and Sues (2007: pp. 92-93), is similar to ZIN PH 2340/16 but less elongated.

\subsection{Manus}

ZIN PH 2343/16 is a slender proximal manual phalanx, possible a left phalanx I-1 (Fig. 8: $\mathrm{L}=43.0, \mathrm{PW}=7.0 ; \mathrm{DW}=6.1$ ), and resembles that element in other troodontids (Barsbold et al., 1987: fig. 2A; Currie and Dong, 2001: fig. 9). Its articular ends are ginglymoid and only slightly expanded mediolaterally relative to the shaft. The proximal end is expanded anterolaterally relative to the shaft. The proximal end is nearly symmetrical in proximal view, with two concave articular surfaces of roughly equal size separated by a ridge (the lateral surface is little wider). The shaft of the phalanx is mediolaterally compressed, with rounded anterior and flattened posterior surfaces. The distal end is slightly asymmetrical, with the medial condyle anteroposteriorly wider than the lateral condyle. The pits for the collateral ligaments are small and confined to the anterior border of the condyles.

\subsection{Pes}

Two distal ends of metatarsal III from Dzharakuduk are referable to Troodontidae: ZIN PH 2341 and 2342/16 (Fig. 9; DW=12.8 and 10.9, respectively). The shaft is triangular in transverse section and bears a sharp posterior crest. It is mediolaterally constricted just proximal to the distal end, widens more proximally, and tapers towards the preserved proximal end proximal to this widening. The anterior side of the shaft is remarkable flat whereas its posteromedial and posterolateral surfaces are concave. The distal end of the phalanx is mediolaterally constricted and somewhat deflected laterally from the long axis of the shaft. Its 
distal condyle is weakly ginglymoid, with a shallow groove separating the condyles. The distal articular surface is slightly asymmetrical, with a larger lateral condyle. The lateral condyle is distinctly larger in one specimen of Troodon formosus (Russell, 1969: fig. 12D), whereas both condyles are similar in size in another specimen (Wilson and Currie, 1985: fig. 2a). On the posterior side of the element, the distal articular surface has the tongue-like extension as is typical for troodontids (Russell, 1969: fig. 13; Wilson and Currie, 1985: fig. 2C; Osmólska, 1987: pl. 54, figs. 2, 3; Currie and Dong, 2001: p. 1762). The proximal end of this extension in ZIN PH 2342/16 is incised by a short longitudinal groove, as in Sinornithoides youngi (Currie and Dong, 2001: fig. 10F), whereas this groove is absent in ZIN PH 2341/16, possibly due to postmortem abrasion. The lateral pits for the collateral ligaments are broad and shallow.

ZIN PH 99/16 (Fig. 10; DW=6.3) is the distinctive second phalanx of the second pedal digit that supported the enlarged pedal ungual in life. The ventral lip of its proximal articular facet forms a distinct "heel." The proximal articular surface of the phalanx is slightly asymmetrical and divided by a distinct median ridge. The phalanx is short and only slightly constricted between its articular ends. Its ginglymoid distal end bears an articular facet with a curvature of about $135^{\circ}$, which extends much farther proximally ventrally than dorsally. The distal condyles are almost symmetrical and separated by a broad groove. The pit for the collateral ligament is deeper on one side; both pits are located more centrally compared with the condition in Dromaeosauridae.

\section{Phylogenetic position of Urbacodon}

To assess the phylogenetic position of Urbacodon we performed a parsimony analysis based on the character-taxon matrix for coelurosaurian theropods published by Gao et al. (2012), with the addition of Gobivenator mongoliensis from the Campanian of Mongolia (Tsuihiji et al., 2014) and Xixiasaurus henanensis from the ?Campanian of China (Lü et al., 2010). The codings for $G$. 
mongoliensis are derived from the online supplementary information file to Tsuihiji et al. (2014). The codings for $X$. henanensis are based on the original description of that taxon. The description of the characters can be found in supplementary information file for Zhang et al. (2008). We did not include in the matrix characters that can only be observed on the partial troodontid braincase CCMGE 466/12457 from Dzharakuduk. These characters will be discussed when the detailed study of this specimen has been completed. The material of Urbacodon can be scored for the following 49 characters $(13.5 \%$ of a total of 363 characters):

20 (1): Maxillary process of premaxilla reduced so that maxilla participates broadly in external naris. Although the premaxilla is not known for Urbacodon, the maxillary fragment ZIN PH 2308/16 lacks a premaxillary facet on its subnarial shelf (Fig. 2A, C). This feature is present in all Troodontidae except Sinovenator changii and Xixiasaurus henanensis (Makovicky and Norell, 2004; Lü et al., 2010). It is likely a maniraptoran synapomorphy, with reversals in Oviraptorosauria and Dromaeosauridae. The maxillary process of the premaxilla in Dromaeosauridae extends further posteriorly to separate the maxilla from the nasal posterior to the external narial fenestra.

27(1): Pronounced, round accessory antorbital fenestra (maxillary fenestra) present. A common coelurosaurian feature reversed in few taxa (Alvarezsauroidea, Therizinosauria).

28(0): Accessory antorbital fossa (maxillary fenestra) situated at the anterior border of the antorbital fossa. In all troodontid taxa the anterior margin of the maxillary fenestra is confluent with the anterior margin of the antorbital fossa. In the original matrix used in this analysis, Byronosaurus jaffei and Gobivenator mongoliensis were coded as having maxillary fenestra situated posterior to the anterior border of the fossa (28[1]). However, what is depicted as a maxillary fenestra in the latter taxon (Tsuihiji et al., 2014: fig. 3) is a foramen perforating the medial wall of the maxillary fenestra. In the holotype of Byronosaurus jaffei this region is damaged (Makovicky et al., 2003: figs. 2, 3), but most likely the anterior margins of the maxillary fenestra and antorbital fossa were confluent. This is a plesiomorphic coelurosaurian 
condition and the derived character state, with the maxillary fenestra situated posterior to the anterior border of antorbital fossa, developed in parallel in several taxa, including Anchiornis huxleyi, Dromaeosauridae, and Sinovenator changi.

29(0). Tertiary antorbital fenestra (promaxillary fenestra) absent. ZIN PH 2308/16 lacks a promaxillary fenestra (Fig. 2C). There is conflicting information about distribution of this character in Troodontidae. Makovicky and Norell (2004) stated that the promaxillary fenestra is absent in all troodontids except Sinovenator changii and Sinornithoides youngi. Witmer (1997) noted that a promaxillary fenestra is present in both Sinornithoides youngi and Zanabazar junior. Bever and Norell (2009: p. 21) indicated the presence of a promaxillary fenestra in Troodon formosus with reference to Currie (1985). However, a promaxillary fenestra is not described in that paper and it clearly absent in the illustration of the maxilla fragment (Currie, 1985: fig. 2). Norell et al. (2009) noted that both Saurornithoides mongoliensis and Zanabazar junior lack the promaxillary fenestra. Gobivenator mongoliensis was coded as having a promaxillary fenestra (Tsuihiji et al., 2014) but this fenestra was neither described nor illustrated for this taxon. The absence of a promaxillary fenestra may be a synapomorphy for troodontids more derived than Sinornithoides youngi.

66(0): Symphyseal region of dentary broad and straight, paralleling lateral margin. The plesiomorphic condition is characteristic for troodontids except Saurornithoides mongoliensis, Troodon formosus, Xixiasaurus henanensis, and Zanabazar junior, in all of which the symphyseal region slightly curves medially (66[1]). This character is correlated with the width of the snout, which is wider in taxa with a more medially curved dentary symphysis. In Gobivenator mongoliensis the dentary symphysis is unknown at present, but, based on its snout proportions, this taxon probably retained the plesiomorphic state of this character.

67(0): Dentary symphyseal region in line with main part of buccal edge. Most troodontids have this plesiomorphic condition. The anterior end of the dentary is weakly downturned in Therizinosauria and distinctly downturned in Oviraptorosauria. The anterior end of the dentary is 
downturned only in Xixiasaurus henanensis (Lü et al., 2010: fig. 3B), similar to the condition in Therizinosauria.

69(0): Posterior end of dentary without posterodorsal process dorsal to mandibular fenestra. Most troodontids with sufficiently known mandibular remains have this plesiomorphic condition. A dorsal process of the dentary above the anterior end of the mandibular fenestra (69[1]) is present in Mei long and Sinovenator changii (Xu et al., 2002; Xu and Norell, 2004). A more derived character state, elongate, strongly arched dorsal process extending over most of the mandibular fenestra (69[2]), is present in Oviraptorosauria.

70(0): Labial face of dentary flat. This state is present in all Coelurosauria except Therizinosauria, which have a lateral ridge on the dentary as well as an inset tooth row (70[1]).

71(0): Dentary subtriangular in lateral view. A typical condition for Coelurosauria except Avialae, Compsognathidae, and Dromaeosauridae, which have subparallel dorsal and ventral margins of the dentary in lateral view (71[1]).

72(1): Nutrient foramina on lateral surface of dentary lie within deep groove. A typically troodontid feature, rarely found in other coelurosaurs except for the dromaeosaurid Buiteraptor gonzalezorum (Makovicky et al., 2005).

83(0): Maxilla toothed. An edentulous maxilla (83[1]) is found in Ornithomimosauria, Oviraptorosauria, and most Avialae.

84(2): Maxillary and dentary teeth all without serrations. Among Troodontidae and related taxa, unserrated teeth are present in Anchiornis huxleyi, Byronosaurus jaffei, Gobivenator mongoliensis, Mei long, Sinovenator changii, Urbacodon spp., and Xixiasaurus henanensis. Among other Coelurosauria unserrated teeth are found in basal Ornithomimosauria and basal Oviraptorosauria retaining teeth, in Alvarezsauroidea, in the dromaeosaurid Buiteraptor gonzalezorum, and in Avialae retaining teeth.

85(1): Dentary and maxillary teeth, large number of small teeth (25 or more in dentary). This state is found in all Troodontidae and related taxa except Anchiornis. Among other 
Coelurosauria this feature is present in Alvarezsauroidea, Therizinosauria, and Buiteraptor gonzalezorum.

88(0): Teeth constricted between root and crown. This state is present in all Troodontidae and related taxa, in Therizinosauria, Alvarezsauroidea, basal Oviraptorosauria retaining teeth, and Avialae with teeth.

89(1): Dentary teeth, anterior dentary teeth smaller, more numerous, and more closely spaced than those in the middle of the tooth row. This is an unambiguous synapomorphy for Troodontidae.

90(0): Dentary lacking distinct interdental plates. There is some confusion in identification of interdental plates in Troodontidae and Dromaeosauridae (Currie, 1987; Varricchio, 1997; Averianov and Sues, 2007; Turner et al., 2012). As currently coded, dentary interdental plates are absent among Coelurosauria in basal Oviraptorosauria (which retain teeth), Alvarezsauroidea, Dromaeosauridae, Troodontidae, and Avialae.

91(1): Premaxillary tooth crowns asymmetrical (D-shaped in cross-section) with flat lingual surfaces. This character state is coded for Urbacodon sp. based on the isolated premaxillary tooth CCMGE 71/12455 (Fig. 4A-D). Similarly shaped premaxillary teeth are present in Byronosaurus jaffei (Makovicky et al., 2003: fig. 4) and Xixiasaurus henanensis (Lü et al., 2010: figs. 2C, 3A1). Elsewhere among Coelurosauria this character state is found in Tyrannosauroidea.

101(0): Cervical and anterior trunk vertebrae amphiplatyan. This plesiomorphic state is characteristic for the majority of Coelurosauria. Opisthocoelous cervical and anterior dorsal vertebrae (101[1]) are found in Tyrannosauroidea and derived Alvarezsauroidea.

102(1): Anterior trunk vertebrae with large hypapophyses. A maniraptoran synapomorphy reversed in Sinovenator changii. 
103(0): Parapophyses of posterior trunk vertebrae flush with neural arch. A plesiomorphic character-state for the majority of Coelurosauria. Parapophyses distinctly projected on pedicels (103(1)) are found in Alvarezsauroidea and Dromaeosauridae.

104(1): Hyposphene-hypantrum articulations in trunk vertebrae present. There is some uncertainty concerning the coding of this feature for Urbacodon sp. Among three dorsal vertebrae referred to Urbacodon sp. from Dzharakuduk (Fig. 5), this region is concealed by matrix on the anterior dorsal ZIN PH 2339/16. Two posterior vertebrae, ZIN PH 893/16 and SPbGU VZ Din 7/2, have a well-developed hypantrum but no hyposphene. Urbacodon sp. is coded as having a hyposphene-hypantrum articulation, which is consistent with the condition in other troodontids (Makovicky and Norell, 2004). A hyposphene-hypantrum articulation has not been described for Talos sampsoni (Zanno et al., 2011), and thus this taxon was coded as lacking this feature. However, only a single dorsal vertebra with a neural arch is known for this taxon (Zanno et al., 2011; fig. 5A, B), and the hyposphene may have been damaged in this specimen. Thus we changed the coding of this character for Talos sampsoni to uncertain in our analysis. The hyposphene-hypantrum articulation is present in all Coelurosauria except derived Alvarezsauroidea and Avialae.

105(1): Zygapophyses of trunk vertebrae placed lateral to neural canal and separated by groove for interspinuous ligaments. A synapomorphy for Maniraptora.

106(1): Middle and posterior dorsal vertebrae pneumatic. On the dorsals referred to Urbacodon sp. the neural arch is pneumatic but the centrum is likely not pneumatized because it lacks pneumatopores. The pneumatopore for the neural arch sinus is placed in the infrapostdiapophyseal depression (Fig. 5F, K). In the original character-taxon matrix Byronosaurus jaffei, Gobivenator mongoliensis, Saurornithoides mongoliensis, and Troodon formosus all were coded as having apneumatic dorsal vertebrae. In Byronosaurus jaffei the centra of anterior dorsals are not pneumatized, but the neural arches are not preserved (Makovicky et al., 2003: p. 21). The dorsal vertebrae of Gobivenator mongoliensis have not been 
fully described (Tsuihiji et al., 2014). According to Zanno et al. (2011) the middle dorsal neural arches are pneumatized in Saurornithoides mongoliensis, Talos sampsoni, and Troodon formosus. This character needs reformulation to distinguish between pneumatization of the centrum and of the neural arch. Currently, Saurornithoides mongoliensis, Talos sampsoni, Troodon formosus, and Urbacodon sp. are coded for the derived state and Byronosaurus jaffei and Gobivenator mongoliensis as unknown. This is a possible synapomorphy for all troodontids more derived than Anchiornis huxleyi, Mei long, and Sinovenator changii. Pneumatic dorsal vertebrae are also present in Dromaeosauridae, Oviraptorosauria, Tyrannosauroidea, and some Avialae.

108(1): Neural spines of dorsal vertebrae expanded to form "spine tables." The distribution of this character among Troodontidae is poorly understood. A well-developed "spine table" is present in Troodon formosus (Makovicky and Norell, 2004; Zanno et al., 2011), whereas the neural spine is only slightly expanded transversely in Talos sampsoni and Urbacodon sp. Gobivenator mongoliensis is coded as having a "spine table" (Tsuihiji et al., 2014), but the actual degree of expansion has not been documented. Outside Troodontidae, transversely expanded neural spines of dorsal vertebrae are present in some Dromaeosauridae. 109(1): Scar for interspinous ligaments terminating below apex of neural spine. This is a common derived feature of Deinonychosauria (Troodontidae + Dromaeosauridae) but it is absent in Sinovenator changii.

119(2): Neural spines on distal caudals form midline sulcus in center of neural arch. A diagnostic troodontid feature present in all taxa more derived than Anchiornis huxleyi, Mei long, and Sinornithoides youngi. In the latter the neural spine becomes rudimentary or disappears on caudal 10 (Russell and Dong, 1994: p. 2167), but the dorsal sulcus was apparently absent on the distal caudals (119[1]). 
120(2): Prezygapophyses of distal caudal vertebrae strongly reduced. A maniraptoran synapomorphy modified in Dromaeosauridae, which have unusually long prezygapophyses. The polarity of this character should be reversed.

197(0): Metatarsals not co-ossified. The metatarsals are co-ossified in most Avialae.

199(1): Distal end of metatarsal III with well-developed ginglymus. In most troodontid taxa the distal condyles of metatarsal III are only weakly separated. This has created confusion regarding the interpretation of this character. According to Makovicky and Norell (2004: p. 192) "none of the distal articulations are ginglymoid in troodontid metatarsi, except in the unnamed Early Cretaceous taxon from Khamryn Us, Mongolia." However, these authors illustrated the metatarsus of Sinovenator changii with a well-developed distal ginglymus on metatarsal III (Makovicky and Norell, 2004: fig. 9.6E), whereas the metatarsal III of the Khamryn Us troodontid figured by Makovicky and Norell (2004: fig. 9.6C) does not have distinct distal condyles. The original codings in the character-taxon matrix are just the opposite: Sinovenator is coded as having non-ginglymoid metatarsal III and the remaining troodontid taxa as having developed ginglymi. The condition in Mei long is polymorphic (Gao et al., 2012). The distal end of metatarsal III is ginglymoid in Sinovenator changii (Xu et al., 2002: fig. 1k), the Khamryn Us troodontid (Barsbold et al., 1987: fig. 2D, E), Sinornithoides youngi (Currie and Dong, 2001: fig. 10A, F), Talos sampsoni (Zanno et al., 2011: fig. 11J, K, I), Linhevenator tani (Xu et al., 2011), Philovenator curriei (Xu et al., 2012: fig. 1M), Gobivenator mongoliensis (Tsuihiji et al., 2014: fig. 2k), Borogovia gracilicrus (Osmólska, 1987: pl. 53, fig. 6, pl. 54, figs. 1, 2, 3), Tochisaurus nemegtensis (Kurzanov and Osmólska, 1991: pls. 2, 3), and Troodon formosus (Russell, 1969: fig. 12B, D; Wilson and Currie, 1985: fig. 2). Saurornithoides mongoliensis was described as having a non-ginglymoid distal articular surface of metatarsal III (Norell et al., 2009: p. 26) but the specimen is poorly preserved and still in articulation with the proximal phalanx (Norell et al., 2009: fig. 20). It is coded as unknown as in the original matrix. 
200(2): In anterior view, metatarsal III is pinched both proximally and through the midshaft. This derived state is found in all Troodontidae except Sinovenator changii, Tyrannosauroidea, advanced Ornithomimosauria and Alvarezsauroidea, Avimimus portentosus, and some Dromaeosauridae.

206(0): Neural spines on posterior dorsal vertebrae in lateral view rectangular or square. A plesiomorphic condition for the majority of Coelurosauria. Anteroposteriorly expanded, fanshaped neural spines (206[1]) are present in Compsognathidae and Anchiornis huxleyi.

217(0): Dentary fully toothed. The dentary has only anterior teeth (217[1]) or is entirely edentulous (217[2]) in Ornithomimosauria, Oviraptorosauria, and Avialae.

224(0): Ventral surface of dentary straight or nearly straight. Ventral surface of dentary deflected strongly posteriorly (224[1]) in Therizinosauria and some Avialae.

228(0): Roots of dentary and maxillary teeth labiolingually compressed. A synapomorphy for Deinonychosauria, a reversal from the condition in outgroup taxa (toothed Ornithomimosauria, Therizinosauria, Alvarezsauroidea, and Avialae), which have roots of maxillary and dentary teeth that are circular in cross-section (228[1]).

230(3): Maxillary and dentary teeth labiolingually flattened and recurved, with crowns in middle of tooth row less than twice as high as basal mesiodistal length. An unambiguous synapomorphy for Troodontidae.

231(0): Dentary teeth not increasing in size anteriorly. Dentary teeth increase in size anteriorly, becoming more conical in shape (231[1]) in Therizinosauria.

253(0): Dentary not bowed. A bowed (concave dorsally) dentary (253(1)) is present in Caenagnathidae and some Dromaeosauridae.

254(0): Meckelian groove of dentary deep. A shallow Meckelian groove (254(1)) is found in Tyrannosauroidea and some Avialae and Dromaeosauridae.

260(1): Dentary teeth implanted in groove. A synapomorphy for Troodontidae. 
261(0): Dentary dentition continues anteriorly to the tip of the dentary. The dentary tooth row terminates before reaching the anterior tip of the dentary (261[1]) in Therizinosauria and Oviraptorosauria retaining teeth.

264(1): Dorsal centra height equal or less than length. In the original matrix two taxa have been coded as having dorsal centra 1.2 or more times taller than long (264[0]): Talos sampsoni and Linhevenator tani. However, the centrum length $(22.9 \mathrm{~mm})$ in Talos sampsoni is nearly equal to the dorsoventral height $(23.2 \mathrm{~mm})$ on the single known dorsal vertebra (Zanno et al., 2011) and thus should be coded as state 1. The dorsals of Linhevenator tani are too poorly preserved for measurements (Xu et al., 2011: fig. 4) and the coding for this taxon is changed here to uncertain. The plesiomorphic character-state is sporadically present among Coelurosauria and possibly without phylogenetic value.

265(0): Posterior dorsal neural spines 1.5 or more times taller than long. In the original data matrix, Troodon formosus was coded as having shorter neural spines on posterior dorsals, less than 1.5 of the length (265[1]). We do not know the source for this coding because the posterior dorsal vertebrae of this taxon have yet to be described. Other troodontid taxa except Anchiornis huxleyi, Mei long, and Sinovenator changii have the plesiomorphic state of this character. The phylogenetic utility of this character is unclear because it is only sporadically found among Coelurosauria.

266(1): Postzygapophyses of middle and posterior dorsal vertebrae extending posterior to centrum. This state is characteristic for all Maniraptora except Therizinosauria and some Dromaeosauridae.

289(0): Medial ligament pits of manual phalanges deep. A shallow medial ligament pit (289[1]) is a synapomorphy for derived Therizinosauria.

295(0): Manual phalanx I-1 straight. A bowed manual phalanx I-1, with a concave palmar surface (295[1]), is present in Anchiornis huxleyi and in some Dromaeosauridae and Avialae. 
321(1): Total length of pedal phalanx II-2 (not including the posteroventral lip if present) twice or less the length of the distal condylar eminence. This derived condition evolved in parallel in Troodontidae (except Anchiornis huxleyi) and derived Dromaeosauridae.

322(1): Pedal phalanx II-2 with transversely wide posteroventral lip. A synapomorphy for Deinonychosauria.

343(0): Dentary ramus elongate. A shortened dentary, not much longer than tall (343[1]), is a synapomorphy for derived Oviraptorosauria.

346(1): Premaxillary teeth unserrated. Distribution of this character is similar to that of character 84(2).

The character-taxon matrix with scores for Urbacodon spp. and various modifications detailed above was analyzed using PRAP, parsimony ratchet analysis using PAUP (Müller, 2007), and PAUP* 4.0b10 (Swofford, 2002). The equal-weight analysis with 10,000 ratchet replications produced 981 most parsimonious trees; the tree statistics are presented in Tab. 1. The strict consensus tree finds almost no resolution among Troodontidae. To increase resolution and recover any phylogenetic signal, a successive weighting analysis (Farris, 1969) was conducted. Using PAUP, the characters were reweighted by the maximum value of rescaled consistency indices (RC), and a heuristic search with 10,000 random sequence addition replicates and TBR (tree bisection and reconnection) branch swapping was performed. During reweighting 303 characters $(83.5 \%)$ got a weight of less than 1 . Tree statistics stabilized after three successive runs of the reweight analysis (Tab. 1). A section of the strict consensus of 1471 trees obtained in the last analysis, showing the interrelationships of Troodontidae, is illustrated in Fig. 11.

On the consensus tree the basal position of Talos sampsoni and Byronosaurus jaffei may be an artifact caused by the lack of cranial data for the former taxon and of postcranial information for the latter. Urbacodon spp. is recovered in a clade of derived Late Cretaceous taxa. Within this clade, it groups with Gobivenator mongoliensis based on a single unambiguous 
synapomorphy: $265(0)$, posterior dorsals with tall neural spines, 1.5 or more times taller than long. This character state has a wider phylogenetic distribution, however, because it is also present in Talos sampsoni. Among other taxa within this clade, the state of this character is known only for Troodon formosus, which is coded in the matrix for the opposite state. We do not know upon which material this coding was scored. Troodontids more derived than Urbacodon spp. and Gobivenator mongoliensis are united by a single unambiguous synapomorphy: 66(1), symphyseal region of dentary slightly curved medially. However, the symphyseal portion of the dentary is not known for Gobivenator mongoliensis but, judging from its rather broad snout, it probably shared this derived character state. Lü et al. (2010) speculated about the existence of an endemic Asian clade of Troodontidae with unserrated dentitions, including Byronosaurus jaffei, Urbacodon spp., and Xixiasaurus henanensis. Gobivenator mongoliensis (Tsuihiji et al., 2014) also has unserrated teeth. However, our analysis did not recover such a clade. Three of the taxa, Urbacodon spp., Gobivenator mongoliensis, and Xixiasaurus henanensis, were found as successive sister taxa to a more exclusive clade of derived troodontids with serrated dentition. However, there is at least one potential synapomorphy for Byronosaurus jaffei, Urbacodon spp., and Xixiasaurus henanensis (unknown for Gobivenator mongoliensis): 91(1), premaxillary tooth crowns asymmetrical (D-shaped in cross-section) with flat lingual surface.

\section{Conclusions}

Three troodontid taxa are currently recognized from the Upper Cretaceous strata of the Kyzylkum Desert in Uzbekistan. An indeterminate troodontid is known from isolated serrated teeth and some postcranial elements from the Cenomanian Khodzhakul Formation in the southwestern Kyzylkum Desert. Surprisingly, the roughly coeval Cenomanian Dzharakuduk Formation at Itemir in the central Kyzylkum Desert has yielded a troodontid with unserrated teeth, Urbacodon itemirensis, which is currently known from a single dentary. This difference 
may reflect faunal provincialism or possibly a slightly younger age of the Dzharakuduk Formation. A taxon currently identified as Urbacodon sp. is known from the Turonian Bissekty Formation of Dzharakuduk in the central Kyzylkum Desert. It is known from isolated teeth, a fragment of a maxilla, partial dentaries, an incomplete braincase, and various postcranial bones. Urbacodon sp. shares a number of troodontid synapomorphies: presence of a subotic recess; reduced basal tubera placed directly under the occipital condyle; maxilla participating in the margin of the external naris; nutrient foramina of the dentary situated within a deep lateral groove; dentary lacking distinct interdental plates; large number of small dentary and maxillary teeth; teeth constricted between root and crown; anterior dentary teeth smaller, more numerous, more closely spaced than those in middle of the tooth row; tall and posterodorsally tapering neural spines on the posterior dorsal vertebrae; and a median sulcus on the neural arch of distal caudal vertebrae. Among Troodontidae, Urbacodon spp. resembles Byronosaurus jaffei, Gobivenator mongoliensis, and Xixiasaurus henanensis in the possession of unserrated teeth and of premaxillary teeth that are D-shaped in cross-section (the latter condition being unknown for Gobivenator mongoliensis). However, phylogenetic analysis did not recover a putative clade of Asian troodontids with unserrated teeth. Urbacodon temirensis differs from other Late Cretaceous troodontids in having a straight dentary that does not curve medially at its symphyseal end.

\section{Acknowledgments}

Fieldwork in Uzbekistan was facilitated by and conducted in cooperation with the Zoological Institute of the National Academy of Sciences of Uzbekistan, particularly D.A. Azimov and Y.A. Chikin. For their efforts in the field, scientific expertise, and camaraderie, we thank A.V. Abramov, J.D. Archibald, G.O. Cherepanov, I.G. Danilov, S. Dominguez, N. Morris, C.M. Redman, A.S. Resvyi, C. Skrabec, P.P. Skutschas, E.V. Syromyatnikova, and D.J. Ward. M. 
Pinsdorf skillfully prepared ZIN PH 2308/16. The field work in 1997-2006 was funded by the National Science Foundation (EAR-9804771 and EAR-0207004 to J.D. Archibald and H.-D. Sues), the National Geographic Society (5901-97 and 6281-98 to J.D. Archibald and H.-D. Sues), and the Navoi Mining and Metallurgy Combinat. The laboratory research by AA is supported by the Russian Scientific Fund (14-14-00015). Two anonymous reviewers provided helpful comments on a draft of the manuscript.

\section{References}

Averianov, A.O., Sues, H.-D., 2007. A new troodontid (Dinosauria: Theropoda) from the Cenomanian of Uzbekistan, with a review of troodontid records from the territories of the former Soviet Union. Journal of Vertebrate Paleontology 27, 87-98.

Barsbold, R., Osmólska, H., Kurzanov, S.M., 1987. On a new troodontid (Dinosauria, Theropoda) from the Early Cretaceous of Mongolia. Acta Palaeontologica Polonica 32, 121-132.

Bever, G.S., Norell, M.A., 2009. The perinate skull of Byronosaurus (Troodontidae) with observations on the cranial ontogeny of paravian theropods. American Museum Novitates 3657, 1-51.

Clemens, W.A., Nelms, L.G., 1993. Paleoecological implications of Alaskan terrestrial vertebrate fauna in latest Cretaceous time at high paleolatitudes. Geology 21, 503-506.

Colbert, E.H., Russell, D.A., 1969. The small Cretaceous dinosaur Dromaeosaurus. American Museum Novitates 2380, 1-49.

Currie, P.J., 1985. Cranial anatomy of Stenonychosaurus inequalis (Saurischia: Theropoda) and its bearing on the origin of birds. Canadian Journal of Earth Sciences 22, 1643-1658.

Currie, P.J., 1987. Bird-like characteristics of the jaws and teeth of troodontid theropods (Dinosauria, Saurischia). Journal of Vertebrate Paleontology 7, 72-81.

Currie, P.J., Dong, Z., 2001. New information on Cretaceous troodontids (Dinosauria, Theropoda) from the People's Republic of China. Canadian Journal of Earth Sciences 38, 1753-1766. 
Farris, J.S., 1969. A successive approximations approach to character weighting. Systematic Zoology 18, $374-385$.

Fiorillo, A.R., 2008. On the occurrence of exceptionally large teeth of Troodon (Dinosauria: Saurischia) from the Late Cretaceous of northern Alaska. Palaios 23, 322-328.

Fiorillo, A.R., Gangloff, R.A., 2000. Theropod teeth from the Prince Creek Formation (Cretaceous) of northern Alaska, with speculations on Arctic dinosaur paleoecology. Journal of Vertebrate Paleontology 20, 675-682.

Fiorillo, A.R., Tykoski, R.S., Currie, P.J., McCarthy, P.J., Flaig, P., 2009. Description of two partial Troodon braincases from the Prince Creek Formation (Upper Cretaceous), North Slope Alaska. Journal of Vertebrate Paleontology 29, 178-187.

Gao, C., Morschhauser, E.M., Varricchio, D.J., Liu, J., Zhao, B., 2012. A second soundly sleeping dragon: new anatomical details of the Chinese troodontid Mei long with implications for phylogeny and taphonomy. PLoS ONE 7, e45203.

Gauthier, J.A., 1986. Saurischian monophyly and the origin of birds. Memoirs of the California Academy of Sciences 8, 1-55.

Gilmore, C.W., 1924. On Troödon validus, an ornithopodous dinosaur from the Belly River Cretaceous of Alberta, Canada. Bulletin of the University of Alberta Department of Geology 1, 1-43.

Godefroit, P., Golovneva, L.B., Shchepetov, S.V., Garcia, G., Alekseev, P., 2009. The last polar dinosaurs: high diversity of latest Cretaceous Arctic dinosaurs in Russia. Naturwissenschaften 96, 495-501.

Kurzanov, S.M., Osmólska, H., 1991. Tochisaurus nemegtensis gen. et sp. n., a new troodontid (Dinosauria, Theropoda) from Mongolia. Acta Palaeontologica Polonica 36, 69-76.

Lü, J., Xu, L., Liu, Y., Zhang, X., Jia, S., Ji, Q., 2010. A new troodontid theropod from the Late Cretaceous of central China, and the radiation of Asian troodontids. Acta Palaeontologica Polonica 55, 381-388.

Makovicky, P.J., Apesteguía, S., Agnolin, F.L., 2005. The earliest dromaeosaurid theropod from South America. Nature 437, 1007-1011.

Makovicky, P.J., Norell, M.A., 2004. Troodontidae. In: Weishampel, D.B., Dodson, P., Osmólska, H. (Eds.), The Dinosauria. Second edition. University of California Press, Berkeley, pp. 184-195. 
Makovicky, P.J., Norell, M.A., Clark, J.M., Rowe, T.B., 2003. Osteology and relationships of Byronosaurus jaffei (Theropoda: Troodontidae). American Museum Novitates 3402, 1-32.

Marsh, O.C., 1881. Classification of Dinosauria. American Journal of Science, Series 3, 23, 81-86.

Müller, K.F., 2007. PRAP, Parsimony Ratchet Analysis using PAUP*. Version 2.0b3. [Updated at http://systevol.nees.unibonn.de/software/PRAP].

Nesov, L.A., 1981a. Amphibians and reptiles in Cretaceous ecosystems of Middle Asia. In: Darevsky, I.S. (Ed.), Questions of herpetology. Fifth All-Union Herpetological Conference. Abstracts of reports. Nauka, Leningrad, pp. 91-92 (in Russian).

Nesov, L.A., 1981b. Cretaceous salamanders and frogs of the Kyzylkum Desert. Trudy Zoologicheskogo Instituta AN SSSR 101, 57-88 (in Russian).

Nesov, L.A., 1985a. New data on the Late Mesozoic vertebrates of the USSR. In: Darevsky, I.S. (Ed.), Questions of herpetology. Sixth All-Union Herpetological Conference. Abstracts of reports. Nauka, Leningrad, pp. 148-149 (in Russian).

Nesov, L.A., 1985b. New mammals from the Cretaceous of the Kyzylkum. Vestnik Leningradskogo Universiteta, Seriya 7, 8-18 (in Russian).

Nesov, L.A., 1988. Assemblages of late Mesozoic and Paleocene vertebrates of Middle Asia. In: Bogdanova, T.N., Oshurkova, M.V. (Eds.), Formation and evolution of continental biotas. Izdatelstvo Nauka, Leningrad, pp. 93-101 (in Russian).

Nesov, L.A., 1992. Review of localities and remains of Mesozoic and Paleogene birds of the USSR and the description of new finds. Russkii Ornitologicheskii Zhurnal 1, 7-50 (in Russian).

Nesov, L.A., 1993. New Mesozoic mammals of Middle Asia and Kazakhstan and comments about evolution of theriofaunas of the Cretaceous coastal plains of Asia. Trudy Zoologicheskogo Instituta RAN 249, 105-133 (in Russian).

Nesov, L.A., 1995. Dinosaurs of northern Eurasia: new data about assemblages, ecology and paleobiogeography. Izdatelstvo Sankt-Peterburgskogo Universiteta, Saint Petersburg (in Russian).

Nesov, L.A., 1997. Cretaceous nonmarine vertebrates of northern Eurasia. (Posthumous edition by L.B. Golovneva and A.O. Averianov). Izdatel'stvo Sankt-Peterburgskogo Universiteta, Saint Petersburg (in Russian). 
Norell, M.A., Makovicky, P.J., Bever, G.S., Balanoff, A.M., Clark, J.M., Barsbold, R., Rowe, T.B., 2009. A review of the Mongolian Cretaceous dinosaur Saurornithoides (Troodontidae: Theropoda). American Museum Novitates 3654, 1-63.

Osmólska, H., 1987. Borogovia gracilicrus gen. et sp. n., a new troodontid dinosaur from the Late Cretaceous of Mongolia. Acta Palaeontologica Polonica 32, 133-150.

Owen, R., 1842. Report on British fossil reptiles. Part II. In: Report of the British Association for Advancement of Science, 11th Meeting, Plymouth, 1841, 60-204.

Russell, D.A., 1969. A new specimen of Stenonychosaurus from the Oldman Formation (Cretaceous) of Alberta. Canadian Journal of Earth Sciences 6, 595-612.

Russell, D.A., Dong, Z., 1994. A nearly complete skeleton of a new troodontid dinosaur from the Early Cretaceous of the Ordos Basin, Inner Mongolia, People's Republic of China. Canadian Journal of Earth Sciences 30, 2163-2173.

Seeley, H.G., 1887. On the classification of the fossil animals commonly named Dinosauria. Proceedings of the Royal Society of London 43, 165-171.

Sereno, P.C., 1997. The origin and evolution of dinosaurs. Annual Review of Earth and Planetary Sciences 25, 435-489.

Swofford, D.L., 2002. PAUP*. Phylogenetic Analysis Using Parsimony (*and Other Methods). Version 4.0. Sinauer Associates, Sunderland.

Tsuihiji, T., Barsbold, R., Watabe, M., Tsogtbaatar, K., Chinzorig, T., Fujiyama, Y., Suzuki, S., 2014. An exquisitely preserved troodontid theropod with new information on the palatal structure from the Upper Cretaceous of Mongolia. Naturwissenschaften 101, 131-142.

Turner, A.H., Makovicky, P.J., Norell, M.A., 2012. A review of dromaeosaurid systematics and paravian phylogeny. Bulletin of the American Museum of Natural History 371, 1-206.

Varricchio, D.J., Jackson, F.D., Borkowski, J.J., Horner, J.R., 1997. Nest and egg clutches of the dinosaur Troodon formosus and the evolution of avian reproductive traits. Nature 385, 247-250.

Varricchio, D.J., Jackson, F.D., Trueman, C.N., 1999. A nesting trace with eggs for the Cretaceous theropod dinosaur Troodon formosus. Journal of Vertebrate Paleontology 19, 91-100. 
Wilson, M.C., Currie, P.J., 1985. Stenonychosaurus inequalis (Saurischia: Theropoda) from the Judith River (Oldman) Formation of Alberta: new findings on metatarsal structure. Canadian Journal of Earth Sciences 22, 1813-1817.

Witmer, L.M., 1997. The evolution of the antorbital cavity of archosaurs: A study in soft-tissue reconstruction in the fossil record with an analysis of the function of pneumaticity. Society of Vertebrate Paleontology Memoir 3, 1-73.

Xu, X., Norell, M.A., 2004. A new troodontid dinosaur from China with avian-like sleeping posture. Nature 431, 838-841.

Xu, X., Norell, M.A., Wang, X., Makovicky, P.J., Wu, X.-C., 2002. A basal troodontid from the Early Cretaceous of China. Nature 415, 780-784.

Xu, X., Tan, Q., Sullivan, C., Han, F., Xiao, D., 2011. A short-armed troodontid dinosaur from the Upper Cretaceous of Inner Mongolia and its implications for troodontid evolution. PLoS ONE 6, e22916.

Xu, X., Zhao, Q., Sullivan, C., Tan, Q.-W., Sander, P.M., Ma, Q.-Y., 2012. The taxonomy of the troodontid IVPP V 10597 reconsidered. Vertebrata PalAsiatica 50, 140-150.

Zanno, L.E., Varricchio, D.J., O'Connor, P.M., Titus, A.L., Knell, M.J., 2011. A new troodontid theropod, Talos sampsoni gen. et sp. nov., from the Upper Cretaceous Western Interior Basin of North America. PLoS ONE 6, e24487.

Zhang, F., Zhou, Z., Xu, X., Wang, X., Sullivan, C., 2008. A bizarre Jurassic maniraptoran from China with elongate ribbon-like feathers. Nature 455, 1105-1108. 


\section{Figure legends}

Fig. 1. Geographic position of (top) and sketch map of the Itemir-Dzharakuduk depression (bottom). The geographic positions of the two occurrences of specimens of Urbacodon (Dzharakuduk Formation at Itemir and Bissekty Formation at Dzharakuduk) are marked by asterisks. 1, Itemir well; 2, Dzharakuduk wells; 3, Kul'beke well; 4, Bissekty well; 5, Khodzhakhmet well. The top illustration is adapted and modified from a United Nations map and the one at the bottom is modified from Averianov and Sues (2007). [Intended for page width]

Fig. 2. ZIN PH 2308/16 (CBI-, 1979), anterior portion of a left maxilla of Urbacodon sp. from the Bissekty Formation (Turonian) of Dzharakuduk, Uzbekistan. A, lateral view; B medial view; C, palatal view; D, posterior view. Abbreviations: aof, antorbital fenestra; en, passage to external naris; idp, interdental plate; mf, maxillary fenestra; ms, maxillary sinus; $\mathrm{N}$, facet for nasal; $\mathrm{ps,}$ palatal shelf; sac, supraalveolar canal; sns, subnarial shelf; facet for vomer. The asterisk marks an opening resulting from breakage of the thin bony wall. Scale bar equals $1 \mathrm{~cm}$. [Intended for page width]

Fig. 3. ZIN PO 4608 (CBI-5a, 1989), fragment of a right dentary of a juvenile individual of Urbacodon sp. from the Bissekty Formation (Turonian) of Dzharakuduk, Uzbekistan. A, dorsal view; B, medial view; C, lateral view. Abbreviation: Mg, Meckelian groove. Scale bar equals 1 mm. [Intended for column width]

Fig. 4. Urbacodon sp., CCMGE 71/12455 (CBI-14), left premaxillary tooth (A-D), and ZIN PH 265/16 (CBI-4v), left anterior dentary tooth (E-H), from the Bissekty Formation (Turonian) at Dzharakuduk, Uzbekistan. A, mesial view; B, lingual view; C, distal view; D, labial view; E, 
labial view; F, distal view; G, lingual view; H, mesial view. Scale bars equal $1 \mathrm{~mm}$. [Intended for page width]

Fig. 5. ZIN PH 2339/16 (CDZH-16), anterior dorsal vertebra (A-E), ZIN PH 893/16 (CBI-14, 1980), posterior dorsal vertebra (F-J), and SPbGU VZ Din 7/2 (CBI-14, 1980), posterior dorsal vertebra (K-O), referable to Urbacodon sp. from the Bissekty Formation (Turonian) of Dzharakuduk, Uzbekistan. A, anterior view; B, lateral view; C, posterior view; D, dorsal view; E, ventral view; F, posterior view; G, lateral view; H, anterior view; I, dorsal view; J, ventral view; $\mathrm{K}$, posterior view; $\mathrm{L}$, lateral view; $\mathrm{M}$, anterior view; $\mathrm{N}$, dorsal view; $\mathrm{O}$, ventral view. Abbreviations: hy, hypapophysis; ipd, infrapostzygapophyseal depression; ns, neural spine; pa, parapophysis. Scale bars equal $1 \mathrm{~cm}$. [Intended for page width]

Fig. 6. USNM 538124 (CBI-14, 1997), posterior caudal vertebra referable to Urbacodon sp. from the Bissekty Formation (Turonian) of Dzharakuduk, Uzbekistan. A, dorsal view; B, anterior view; C, lateral view; D, posterior view; E, ventral view. Scale bar equals $1 \mathrm{~cm}$. [Intended for column width]

Fig. 7. ZIN PH 2340/16 (CBI-), posterior caudal vertebra referable to Urbacodon sp. from the Bissekty Formation (Turonian) of Dzharakuduk, Uzbekistan. A, anterior view; B, dorsal view; C, lateral view; D, posterior view; E, ventral view. Scale bar equals $1 \mathrm{~cm}$. [Intended for column width]

Fig. 8. ZIN PH 2343/16 (CBI-14, 2004), left manual phalanx I-1 referable Urbacodon sp. from the Bissekty Formation (Turonian) of Dzharakuduk, Uzbekistan. A, lateral view; B, proximal view; C, anterior view; D, distal view; E, medial view. Scale bar equals $1 \mathrm{~cm}$. [Intended for column width] 
Fig. 9. ZIN PH 2342/16 (CBI-17, 1989), distal portion of right metatarsal III referable to Urbacodon sp. from the Bissekty Formation (Turonian) of Dzharakuduk, Uzbekistan. A, anterior view; B, medial view; C, posterior view; D, lateral view; E, distal view. Scale bar equals $1 \mathrm{~cm}$. [Intended for column width]

Fig. 10. ZIN PH 99/16 (CBI-14, 1980), pedal phalanx II-2 referable to Urbacodon sp. from the Bissekty Formation (Turonian) of Dzharakuduk, Uzbekistan. A, dorsal view; B, lateral or medial view; C, ventral view. Scale bar equals $1 \mathrm{~cm}$. [Intended for column width]

Fig. 11. Part of the strict consensus tree of 1471 most parsimonious trees produced by PAUP reweighting character analysis, showing the interrelationships of Troodontidae including Urbacodon. [Intended for page width] 

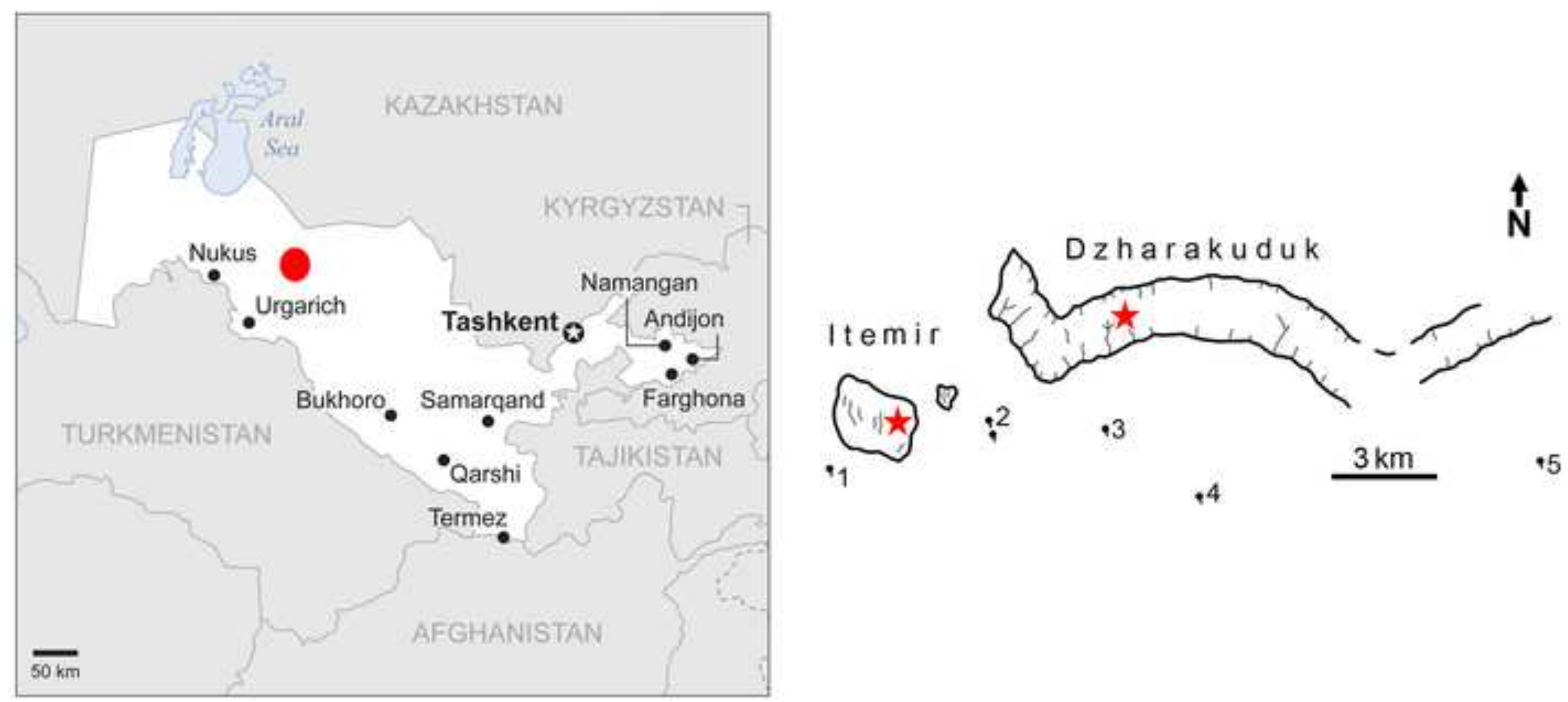
A

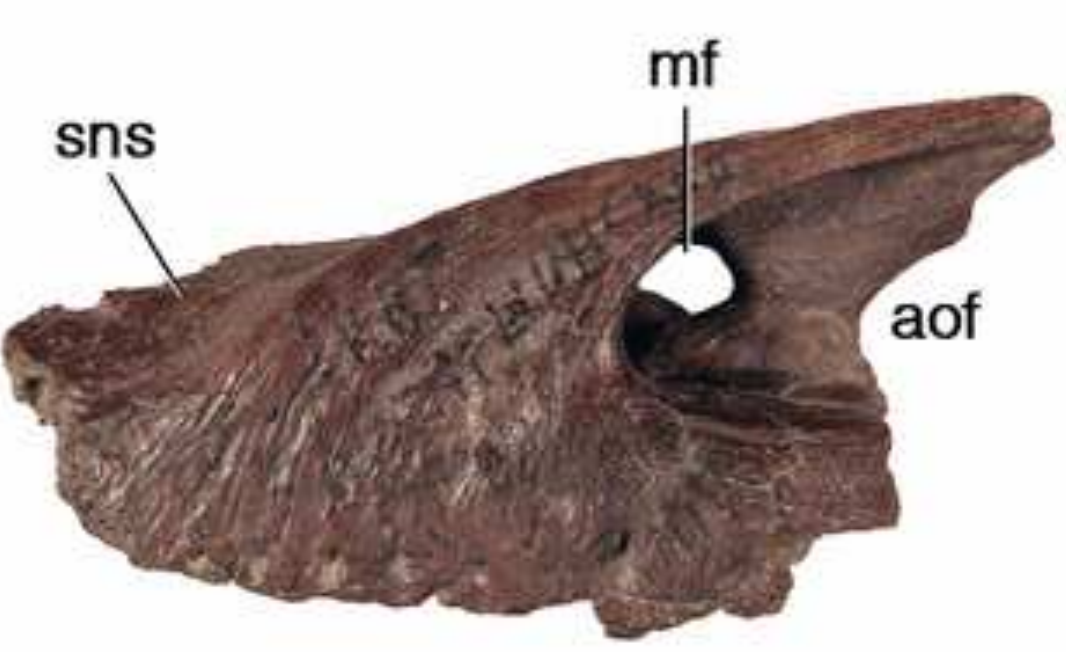

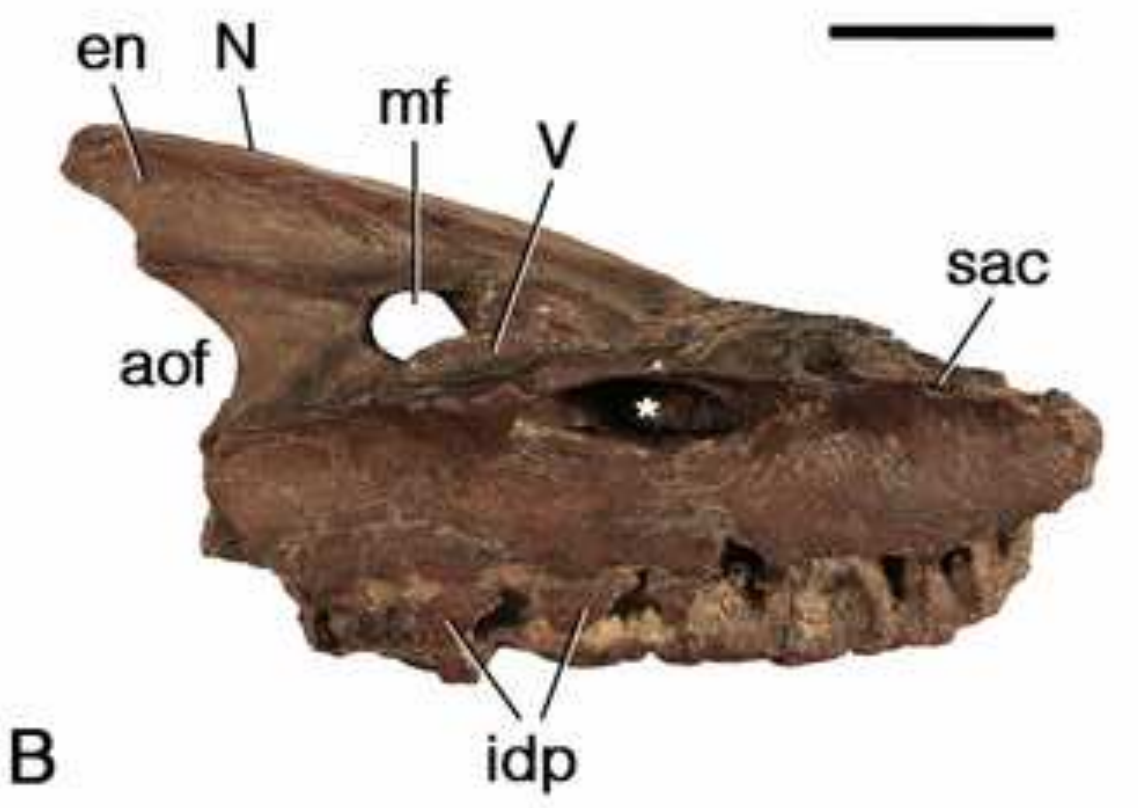

B
C
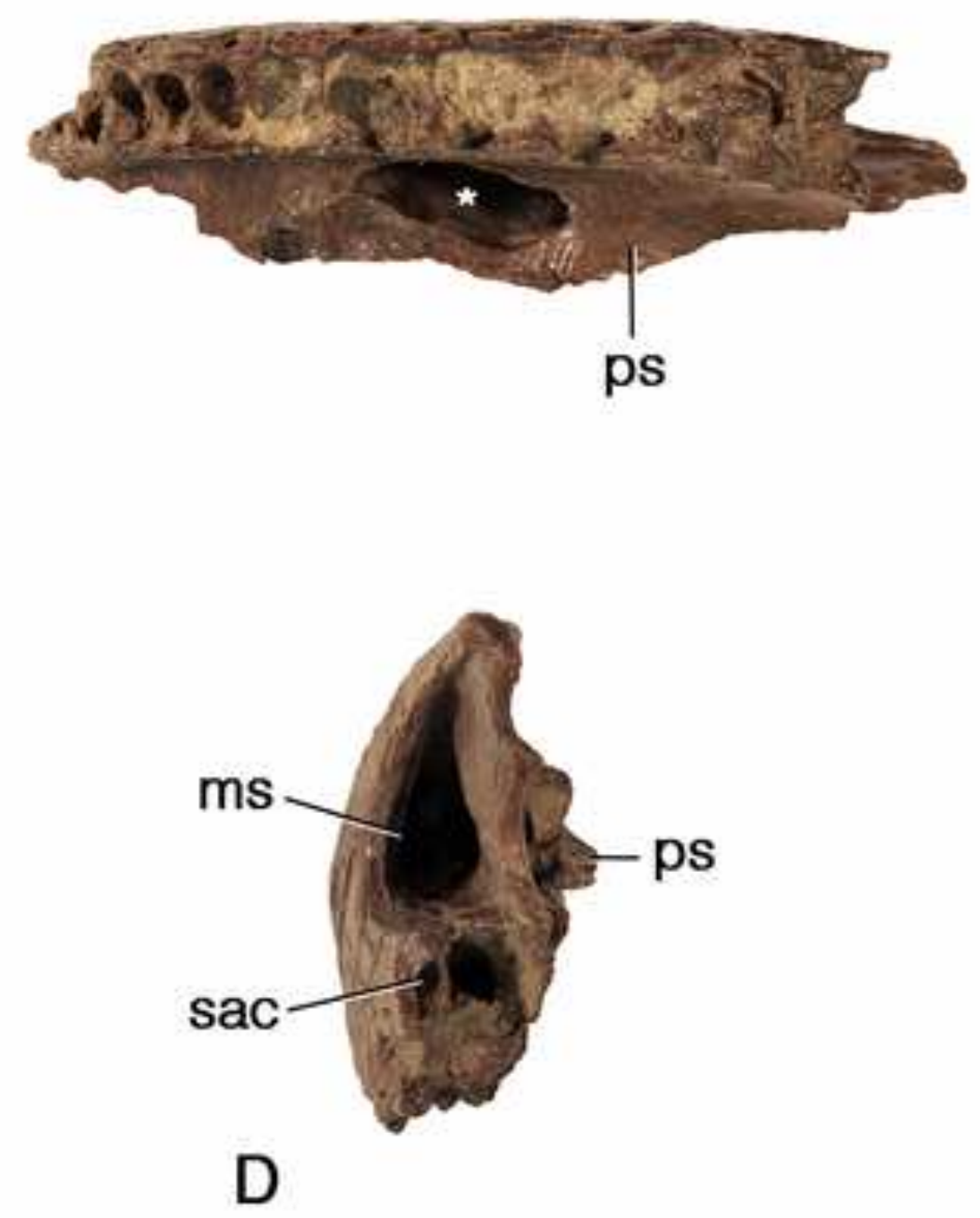

D 


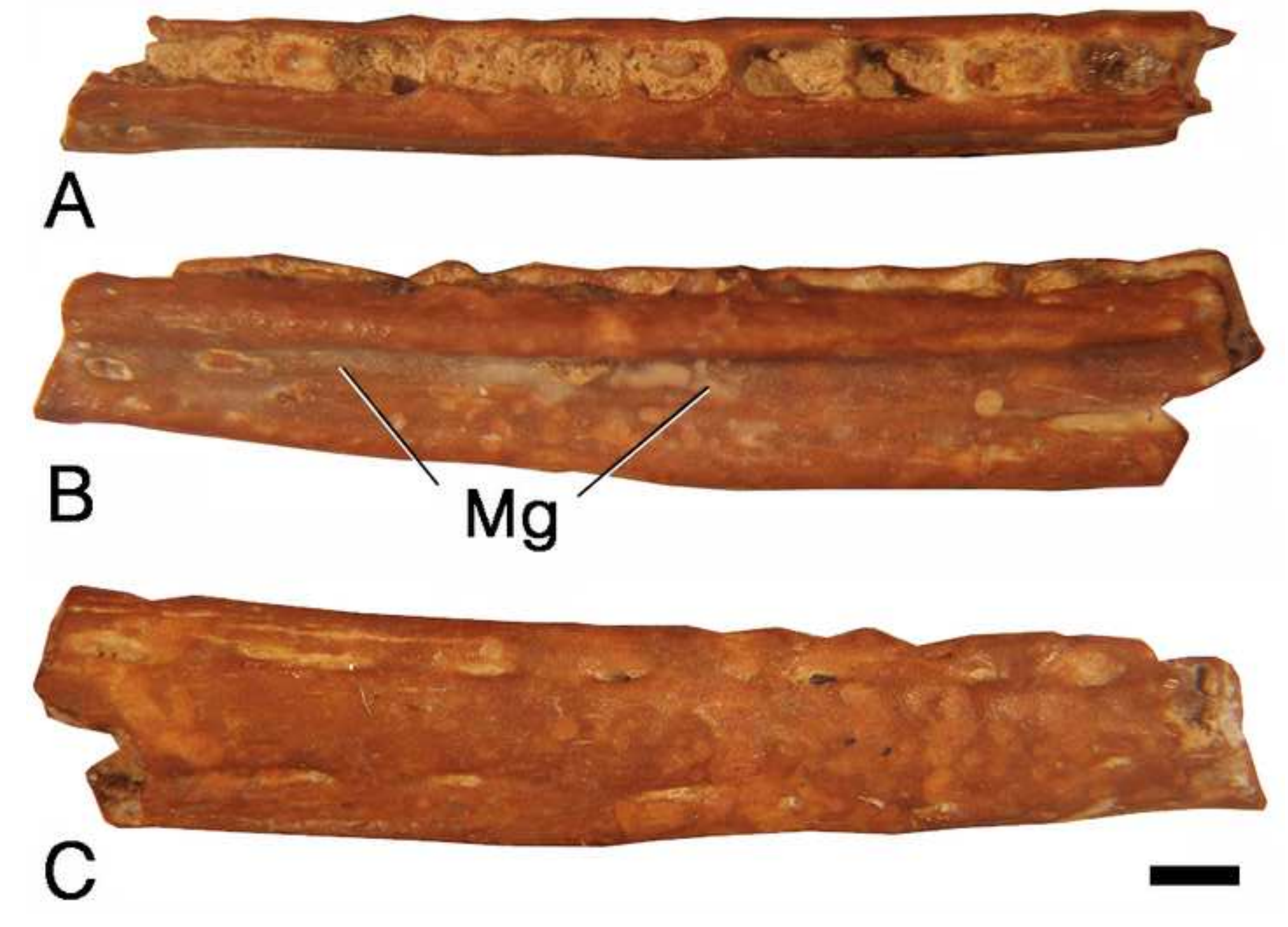

A
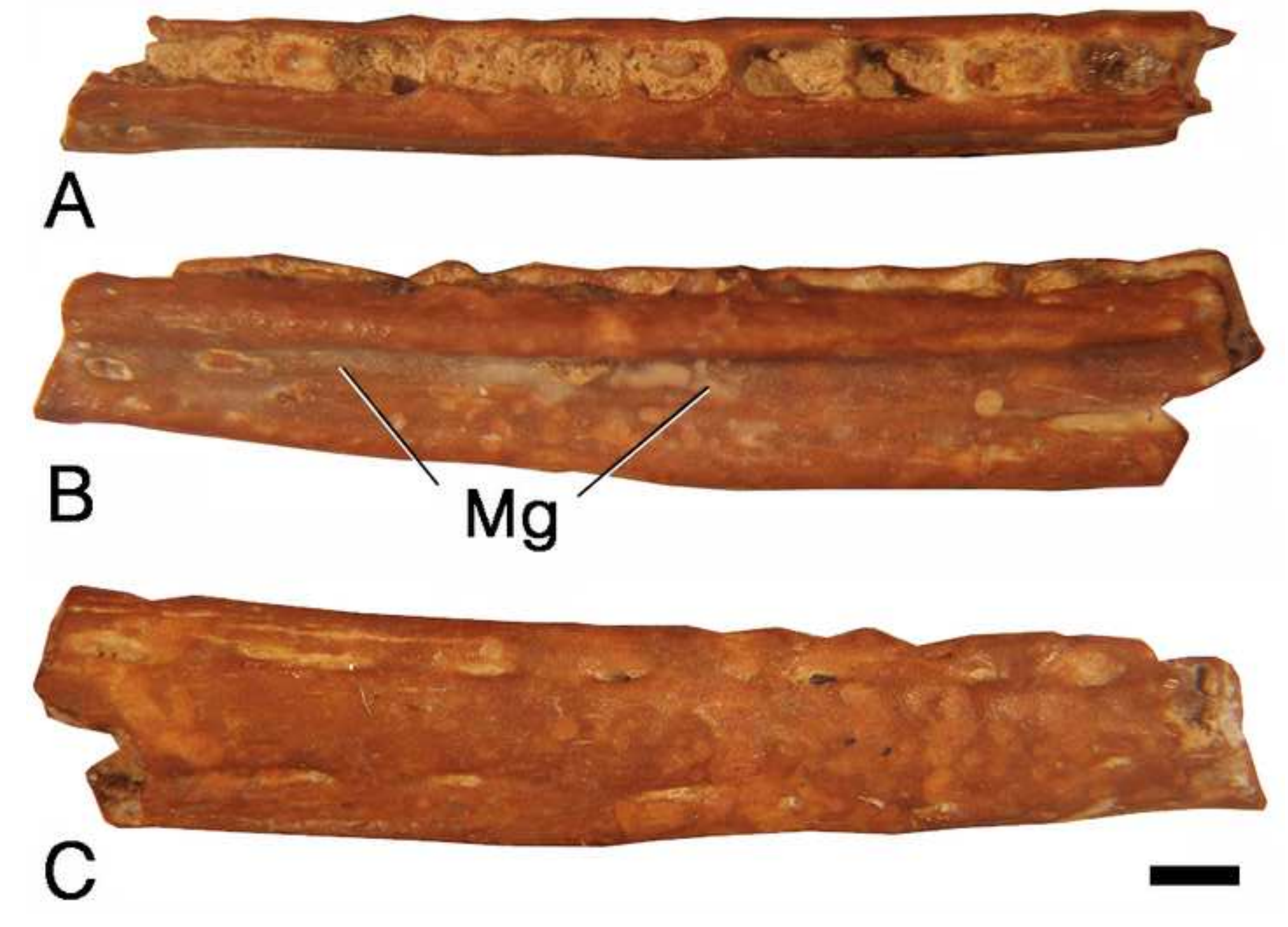

$\mathrm{Mg}$
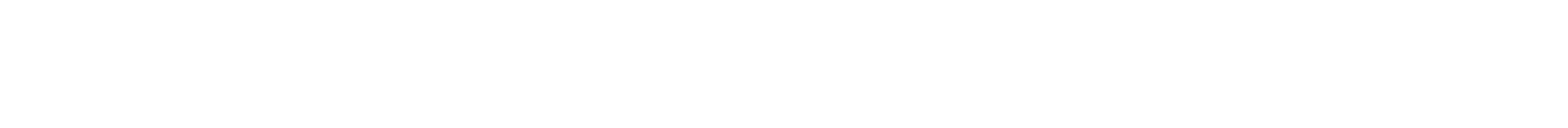

.

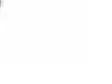




\section{Figure 4}
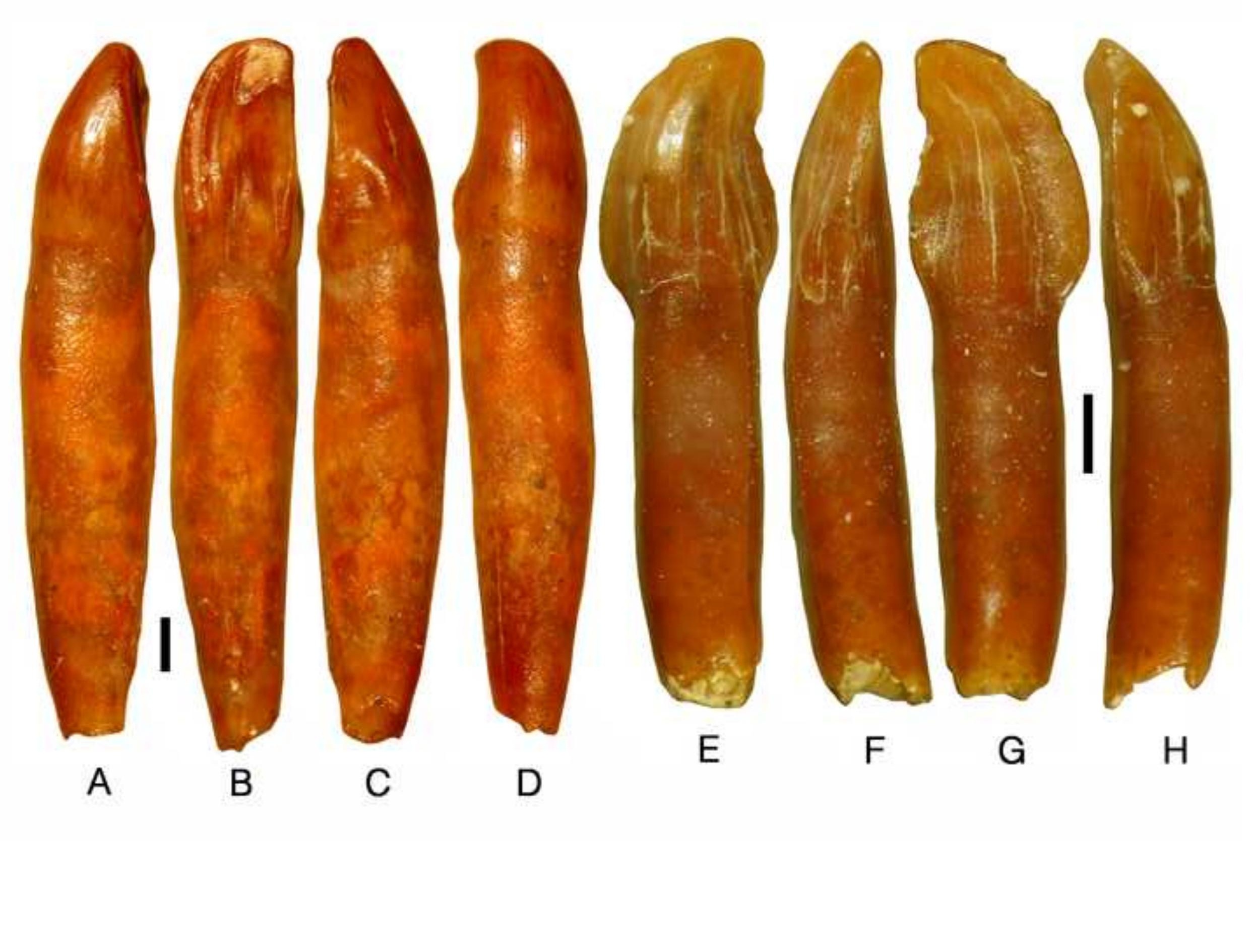


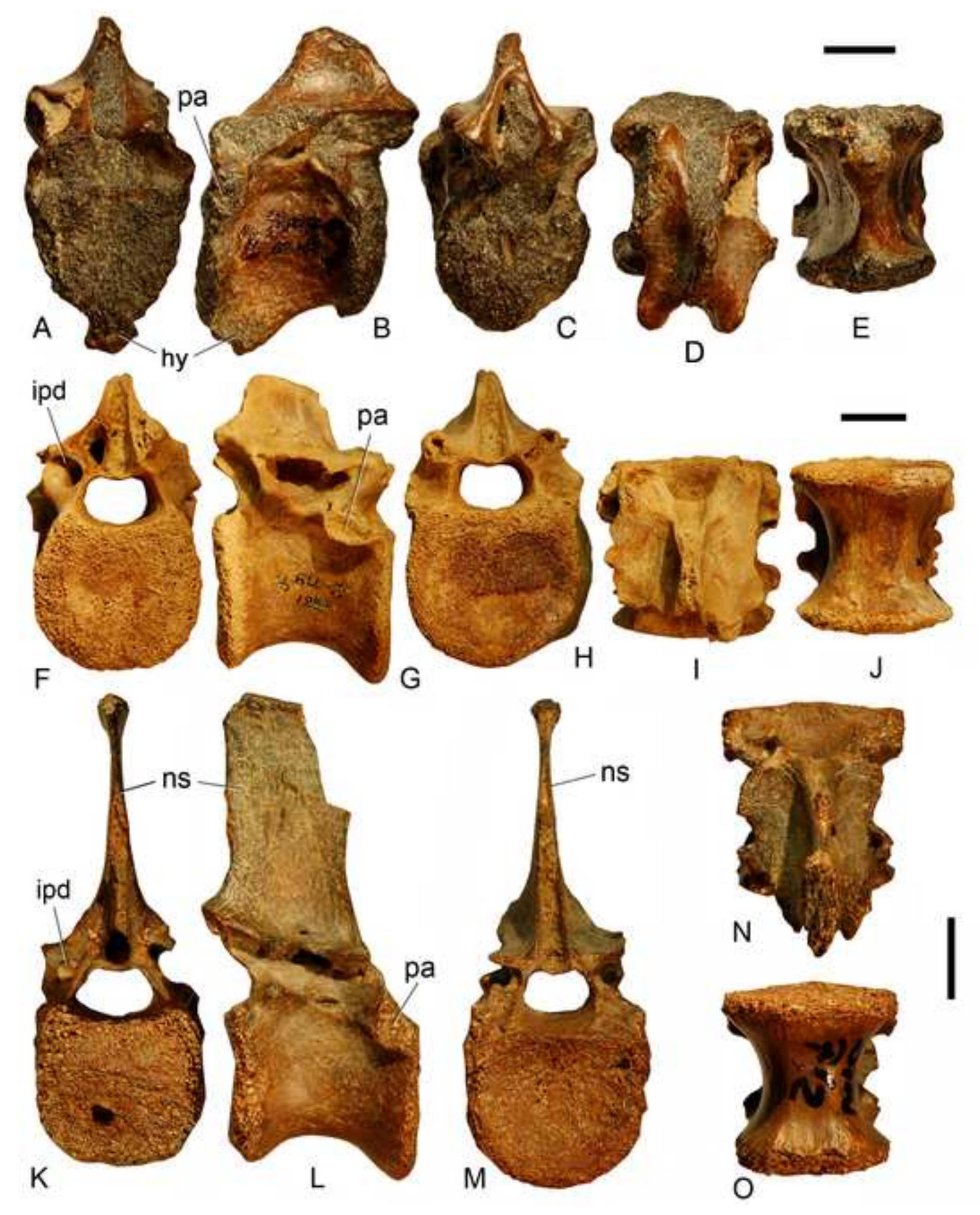

Figure 5

Figure
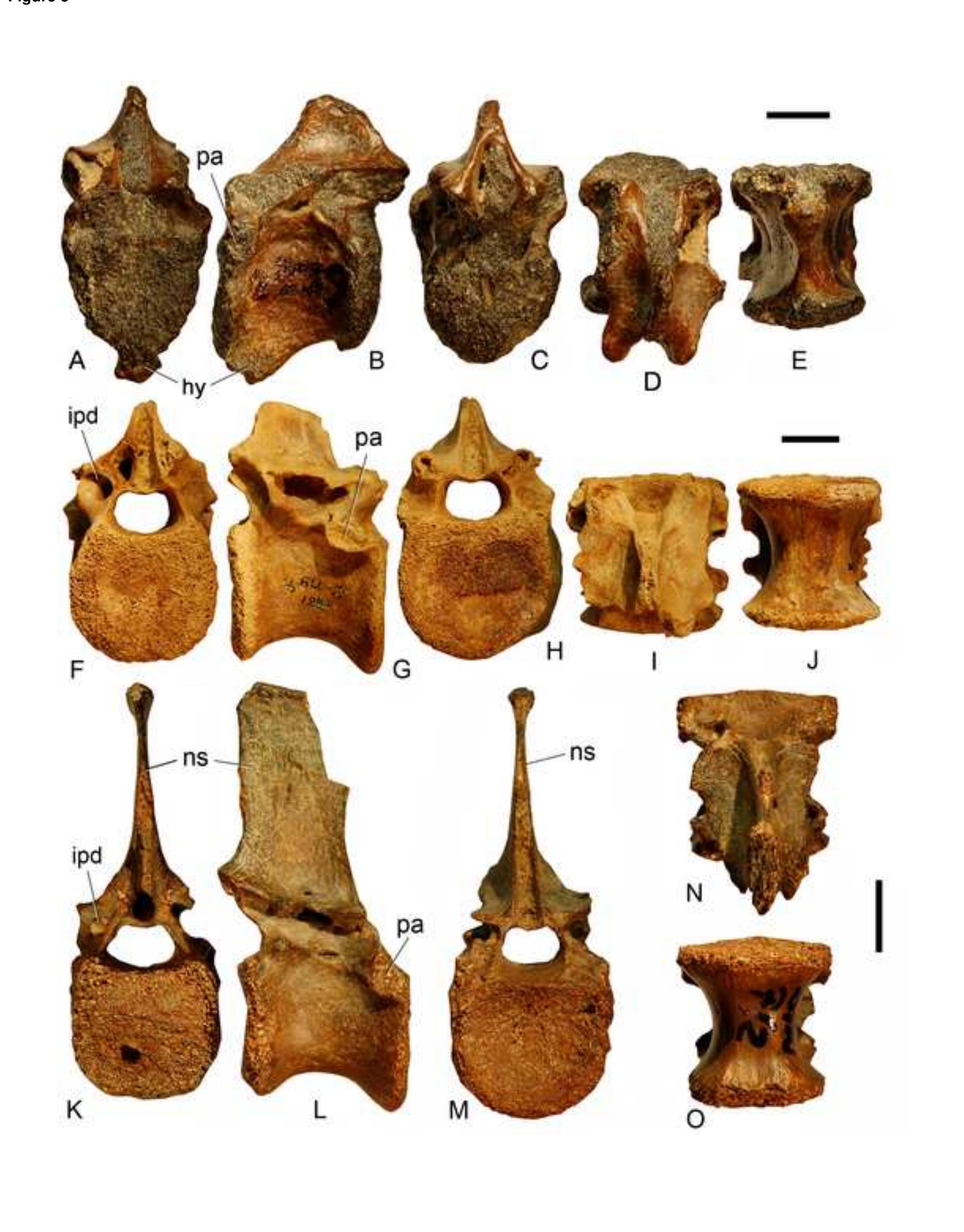
A
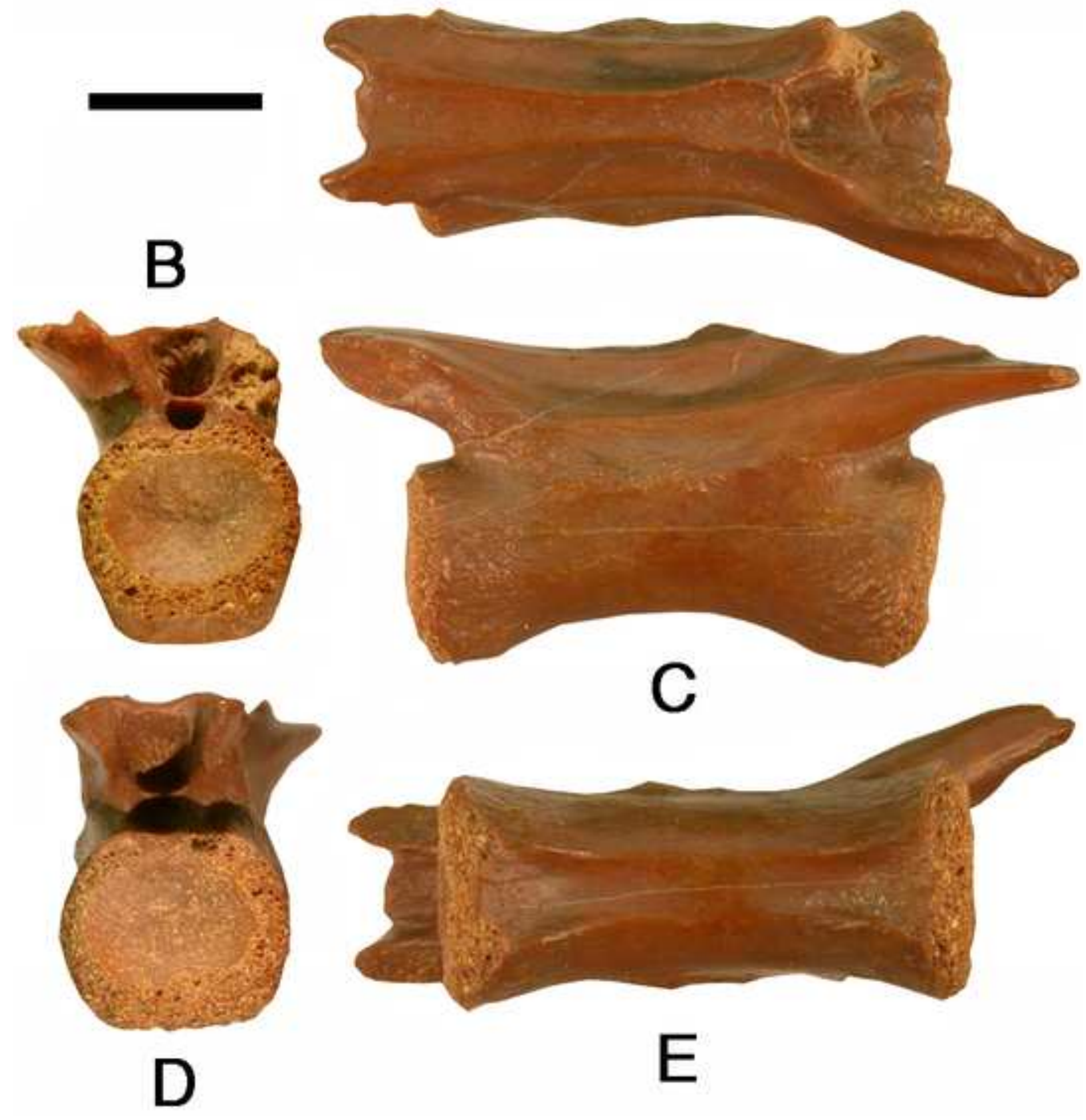

Figure 6 
B

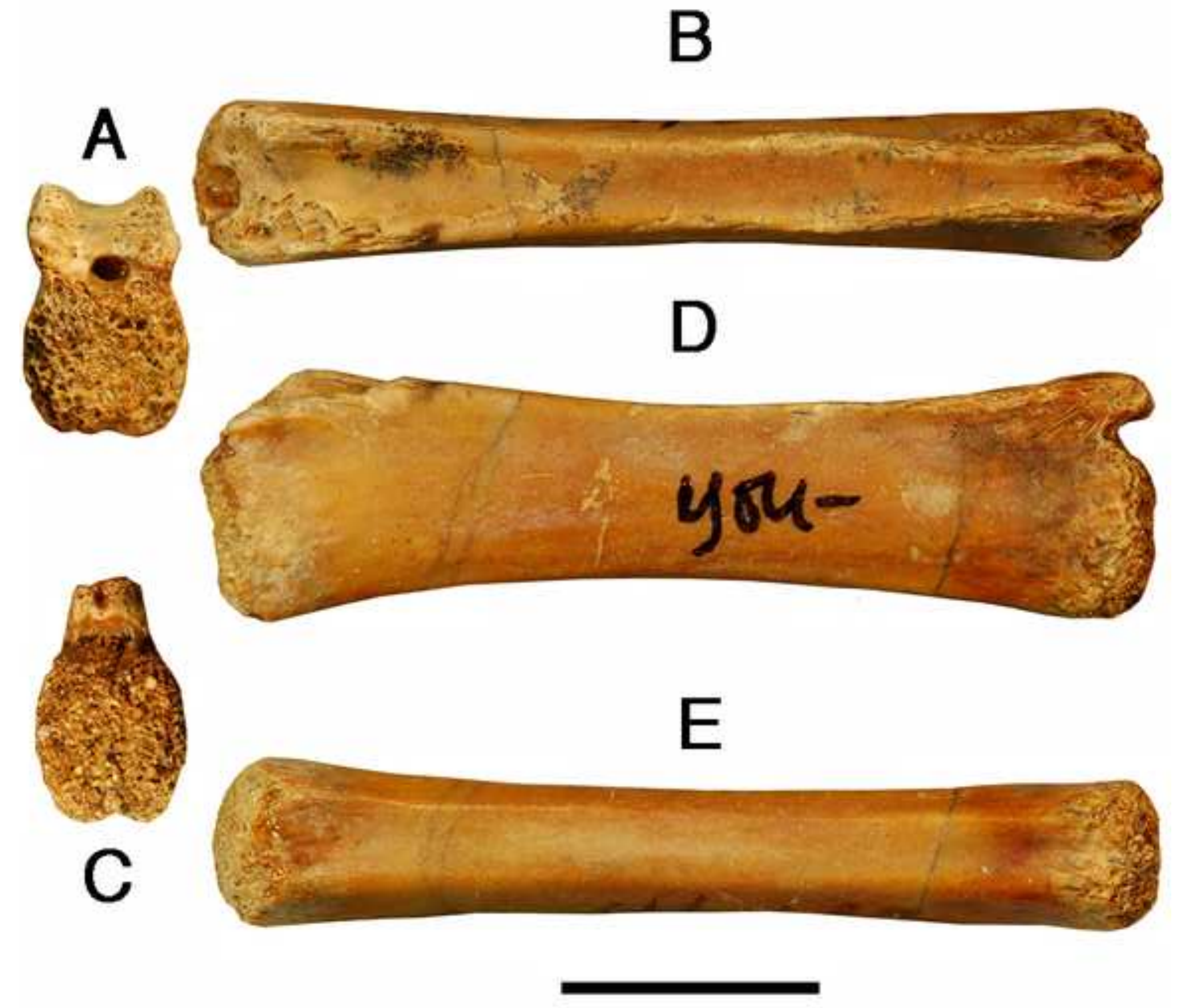




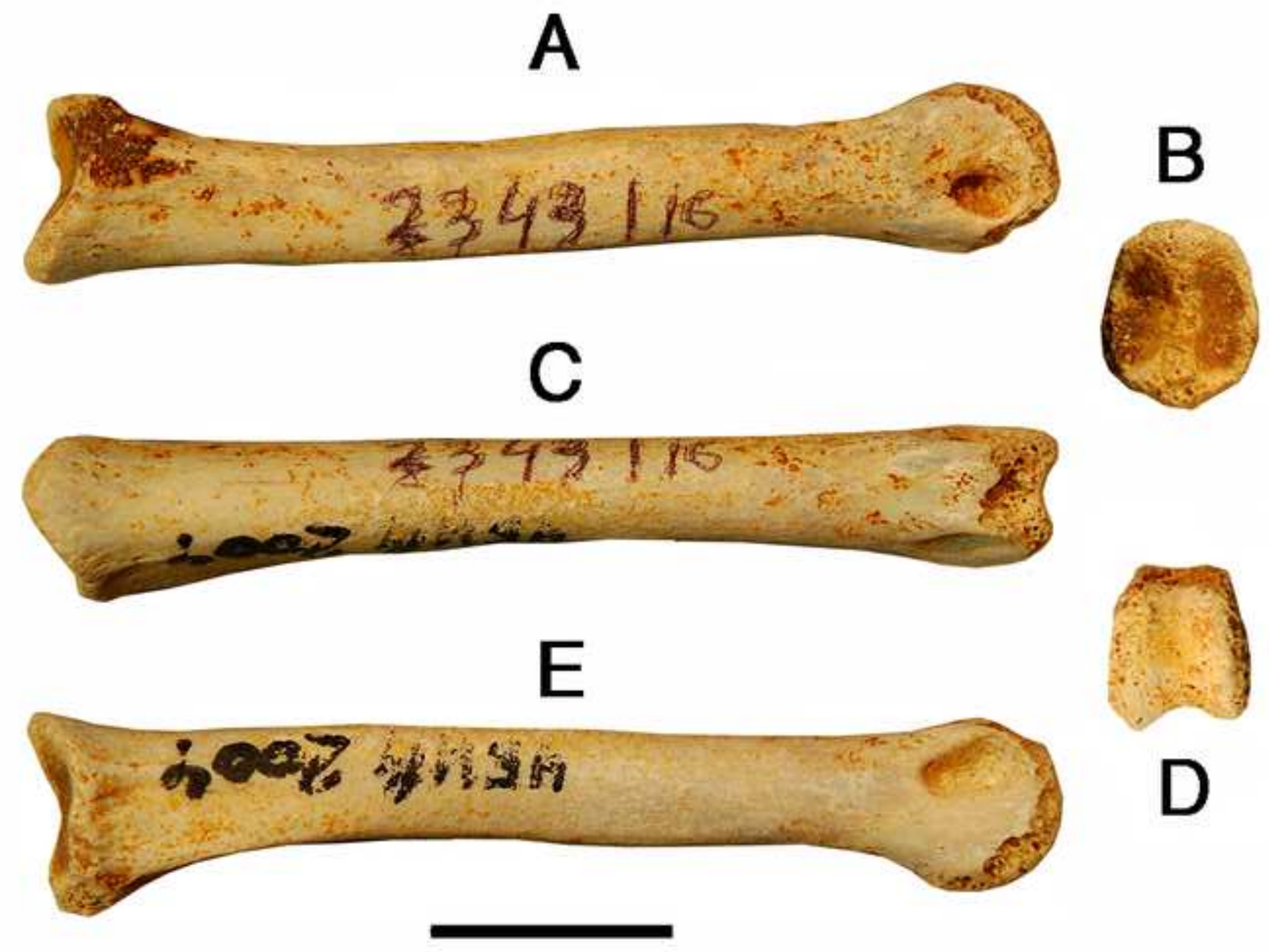

A

C

D

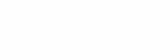


D
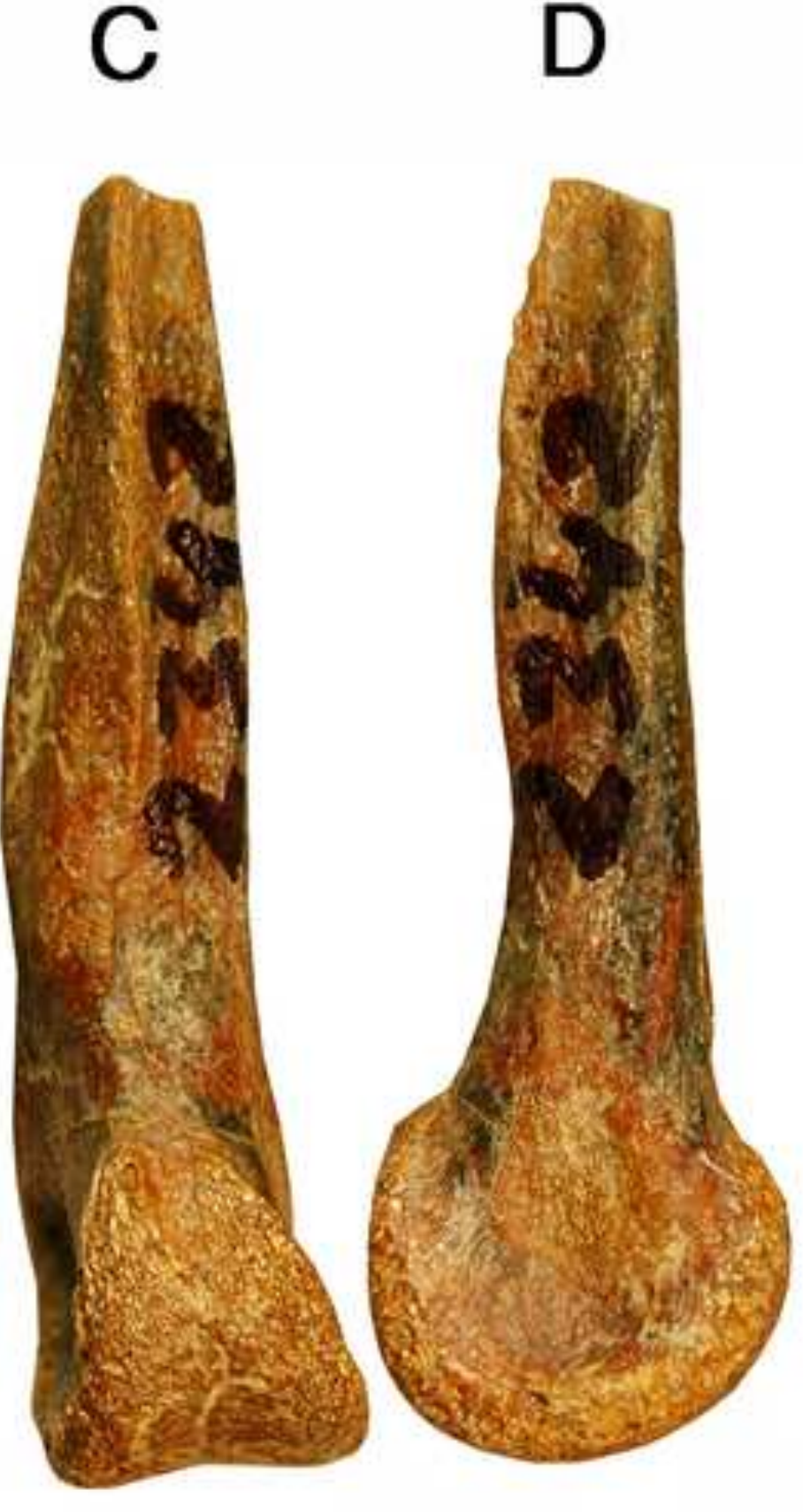

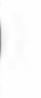
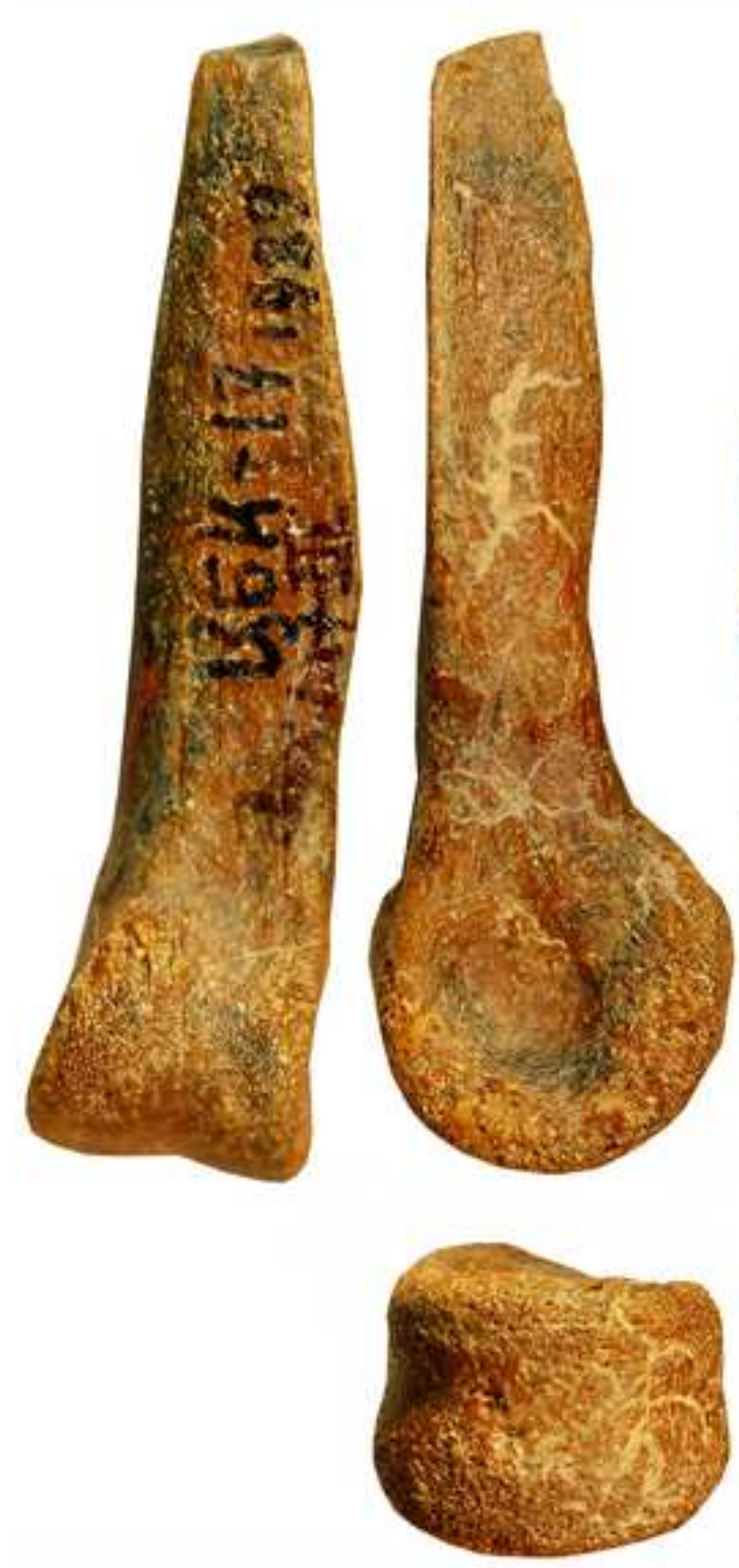

A B C

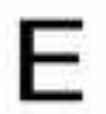

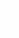
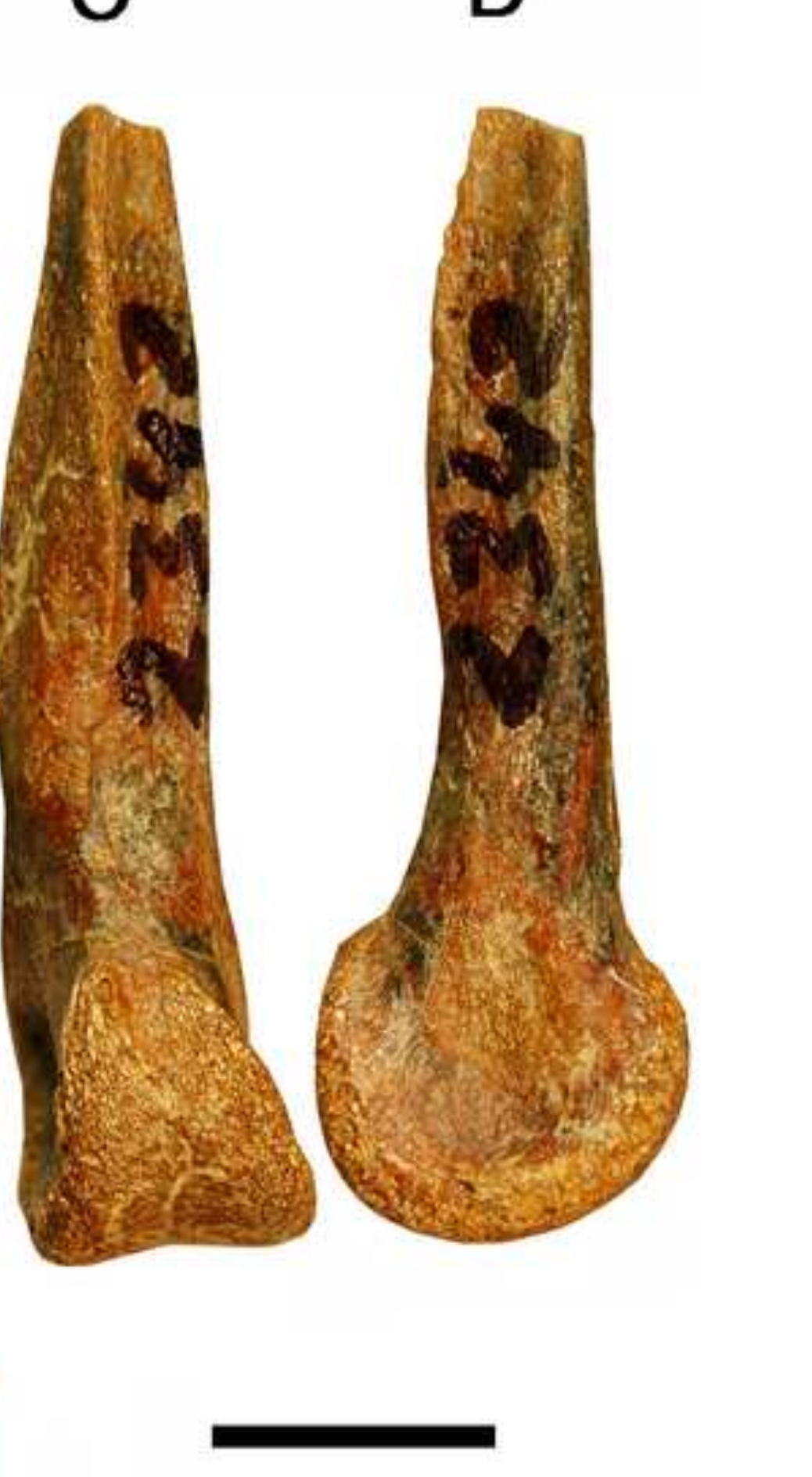
A
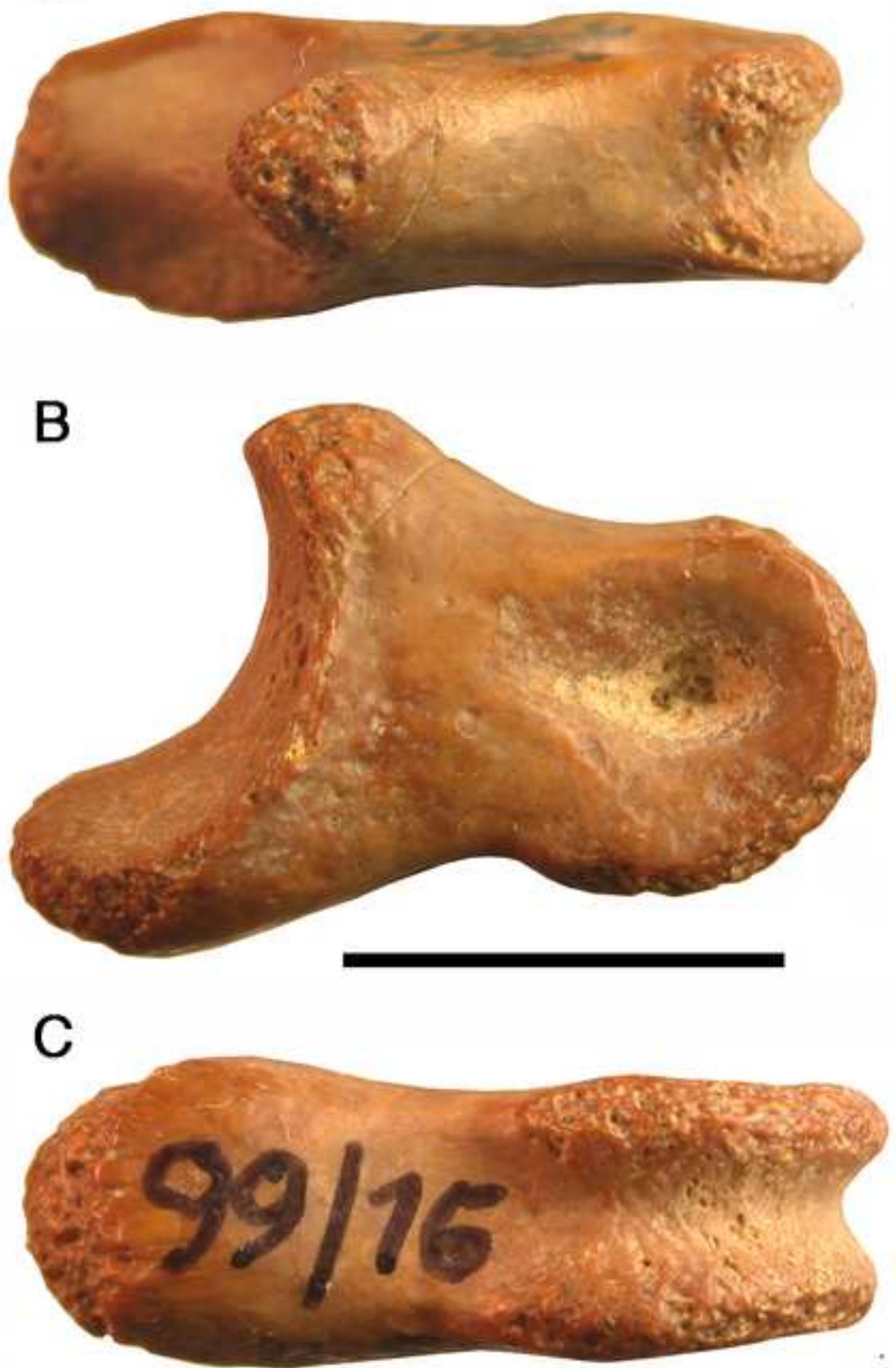


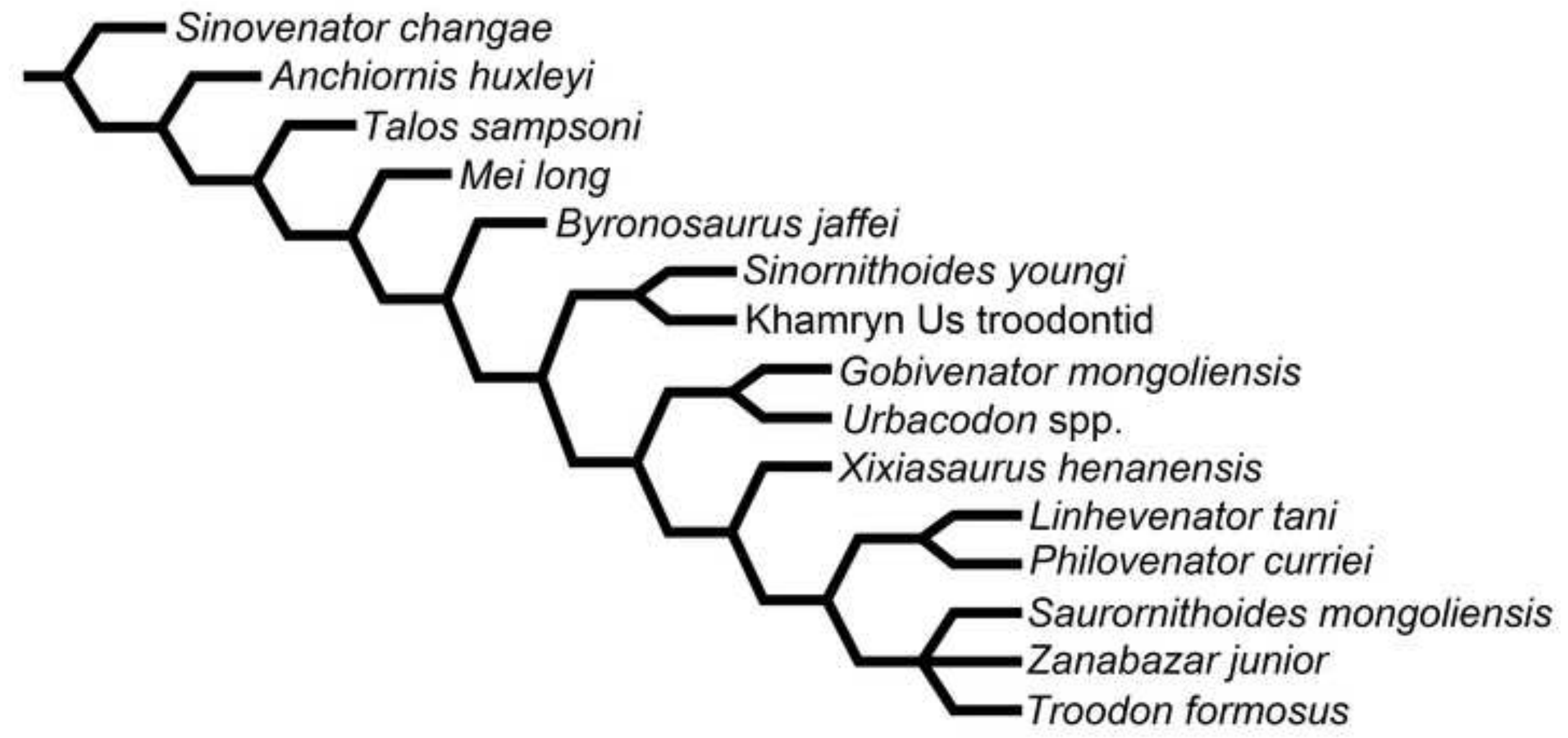


Table 1. Statistics for equal weight(PRAP and PAUP) and reweight (PAUP) analyses. [Intended for page width]

\begin{tabular}{|l|l|l|l|l|}
\hline Parameters & $\begin{array}{l}\text { Equal } \\
\text { weight } \\
\text { analysis }\end{array}$ & $\begin{array}{l}\text { Reweight } \\
\text { analysis } \\
1\end{array}$ & $\begin{array}{l}\text { Reweight } \\
\text { analysis } \\
2\end{array}$ & $\begin{array}{l}\text { Reweight } \\
\text { analysis } \\
3\end{array}$ \\
\hline $\mathrm{N}$, number of trees & 981 & 1269 & 1469 & 1471 \\
\hline $\mathrm{L}$, tree length & 1351 & 331.4 & 327.8 & 327.8 \\
\hline $\mathrm{Cl}$, consistency index & 0.329 & 0.498 & 0.497 & 0.497 \\
\hline $\mathrm{HI}$, homoplasy index & 0.671 & 0.502 & 0.503 & 0.503 \\
\hline $\mathrm{RI}$, retention index & 0.743 & 0.842 & 0.843 & 0.843 \\
\hline $\begin{array}{l}\mathrm{RC} \text {, rescaled consistency } \\
\text { index }\end{array}$ & 0.245 & 0.419 & 0.422 & 0.422 \\
\hline
\end{tabular}

